University of Louisville

ThinkIR: The University of Louisville's Institutional Repository

Electronic Theses and Dissertations

8-2015

\title{
Identifying Hepatocellular Carcinoma (HCC) cells with cancer stem cell-like properties.
}

Harshulkumar M. Pandit

University of Louisville

Follow this and additional works at: https://ir.library.louisville.edu/etd

Part of the Pharmacy and Pharmaceutical Sciences Commons

\section{Recommended Citation}

Pandit, Harshulkumar M., "Identifying Hepatocellular Carcinoma (HCC) cells with cancer stem cell-like properties." (2015). Electronic Theses and Dissertations. Paper 2211.

https://doi.org/10.18297/etd/2211

This Master's Thesis is brought to you for free and open access by ThinkIR: The University of Louisville's Institutional Repository. It has been accepted for inclusion in Electronic Theses and Dissertations by an authorized administrator of ThinkIR: The University of Louisville's Institutional Repository. This title appears here courtesy of the author, who has retained all other copyrights. For more information, please contact thinkir@louisville.edu. 


\title{
IDENTIFYING HEPATOCELLULAR CARCINOMA (HCC) CELLS WITH CANCER STEM CELL-LIKE PROPERTIES
}

\author{
By \\ Harshulkumar M. Pandit \\ B.Sc., Biotechnology, Sardar Patel University, India, 2004 \\ M.Sc., Biochemistry, M. S. University of Baroda, India, 2007
}

\author{
A Thesis Submitted to the Faculty of the \\ School of Medicine of the University of Louisville \\ In Partial Fulfillment of the Requirements \\ For the Degree of
}

Master of Science in Pharmacology and Toxicology

\author{
Department of Pharmacology and Toxicology \\ University of Louisville \\ Louisville, Kentucky
}

August, 2015 



\title{
IDENTIFYING HEPATOCELLULAR CARCINOMA (HCC) CELLS WITH CANCER STEM CELL-LIKE PROPERTIES
}

\author{
By
}

Harshulkumar M. Pandit

A Thesis Approved on

April 17, 2015

By the following Thesis Committee:

Robert C.G. Martin II, MD, Ph.D., FACS

David Hein, Ph.D.

Aruni Bhatnagar, Ph.D.

Haribabu Bodduluri, Ph.D.

Yong Li, Ph.D. 


\section{ACKNOWLEDGEMENTS}

I would like to sincerely thank my mentor, Dr. Robert C.G. Martin, for providing his insights, guidance, encouragement, and offering me this valuable and amazing opportunity to work in his lab in the field of Hepatocellular Carcinoma (HCC). I would also like to express my deepest gratitude to Dr. Yan $\mathrm{Li}$, who provided invaluable help and continuous support on every step of this project. My gratitude also goes to my committee members, Dr. David Hein, Dr. Aruni Bhatnagar, Dr. Haribabu Bodduluri, and Dr. Yong Li for their valuable feedback and assistance. A special thanks to my lab-mates, Suping Li, Dr. Gordon Cui, Dr. Zhang, Saline Li, and the rest of the Martin lab for making my time in the lab enjoyable and for helping me when I needed it. I am also very grateful to my wife, Reema, my parents, my family, and my friends for their love and continuous support. 


\title{
ABSTRACT \\ IDENTIFYING HEPATOCELLULAR CARCINOMA (HCC) CELLS WITH CANCER STEM CELL-LIKE PROPERTIES
}

\author{
Harshulkumar M. Pandit
}

April 17, 2015

Hepatocellular Carcinoma ( $\mathrm{HCC})$ is a challenging condition to treat in the clinic due to its distinct tumor phenotype, aggressive growth, and chemotherapy resistance. Cancer Stem Cells (CSCs) are a poorly differentiated subpopulation of cells within the tumor microenvironment, and role of CSCs in tumor initiation and chemotherapy resistance is not well understood in HCC. In this study, we have successfully identified HCC cells with CSC-like properties that showed resistance to Doxorubicin. Using the established serum free culture techniques, we have enriched CSC-like cells among hepatocellular cancer cells. These enriched cells exhibit all CSC-like properties i.e. self-renewal capability, anchorage independent growth with retained proliferation property and resistance to Doxorubicin. We confirmed expression of CSC surface markers (EpCAM, CD90, CD44, CD133) and functional markers (ALDH activity and dye exclusion properties) in enriched HCC-CSCs. Preliminary in vivo data in our mouse 
models supports that spheroid forming CSCs show higher rate of tumor proliferation compared to untreated (non-spheroid forming) HCC cells. Wnt/ $\beta$ catenin pathway components were also found to be overexpressed in CSCs when compared to non spheroids. Analysis of 24 paired human specimens from HCC tissues by IHC showed higher EpCAM expression, and Western Blot analysis suggested concomitant changes in $\beta$-catenin and EpCAM levels. In conclusion: (1) we have successfully induced and identified HCC cells with CSClike properties; (2) Aberrant $\beta$-catenin up-regulation mediated Wnt/ $\beta$-catenin signaling activation was observed in enriched hepatoma spheroids. 


\section{TABLE OF CONTENTS}

PAGE

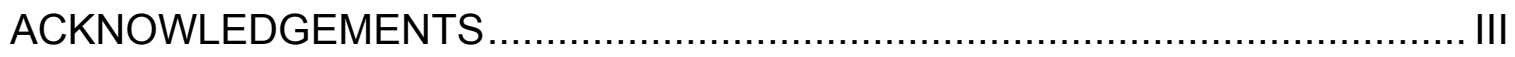

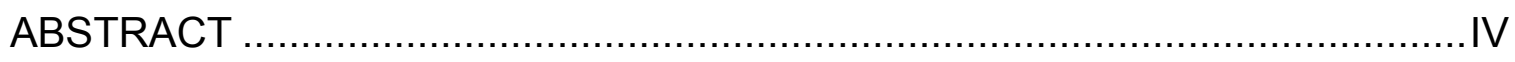

LIST OF FIGURES $\ldots \ldots \ldots \ldots \ldots \ldots \ldots \ldots \ldots \ldots \ldots \ldots \ldots \ldots \ldots \ldots \ldots \ldots \ldots \ldots \ldots \ldots \ldots \ldots . . .1 \mathrm{VII}$

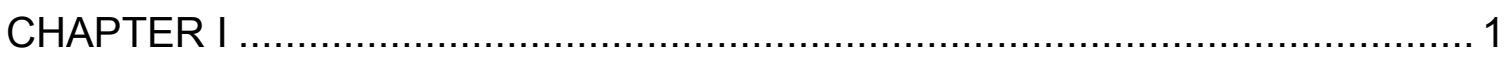

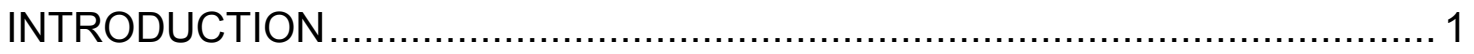

Hepatocellular Carcinoma (HCC):............................................ 1

Risk Factors, Diagnosis and Treatment Modalities: ................................ 2

Cancer Stem Cell (CSC) Model and HCC:......................................... 3

Wnt/ $\beta$-catenin Signaling, CSCs, and HCC: ...................................... 5

Research Direction and Significance of Our Study: ............................ 6

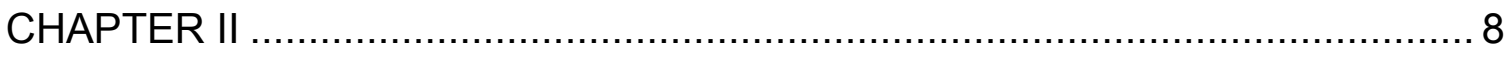

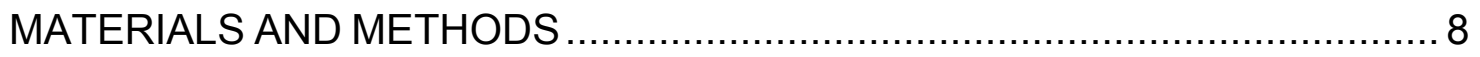

Cell Lines and Animal Models:............................................... 8

Cell Culture and Spheroid Formation: ............................................ 8

Self-Renewal Assay:........................................................... 9

Cell Proliferation Assay: ............................................................. 10

Doxorubicin (Adriamycin) Resistance Assay:...................................... 10

Flow-Cytometry Analysis:....................................................... 11

Immunocytochemistry (ICC) Staining:.............................................. 12

Aldefluor Assay for ALDH Activity: ............................................... 13

Hoechst 33342 Efflux Assay: ............................................. 14

Protein Extraction and Western Blot: .......................................... 14

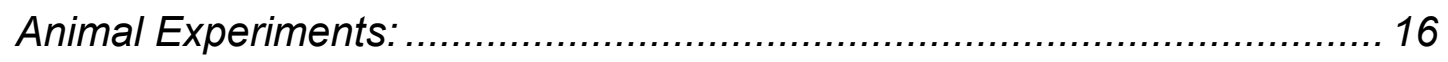




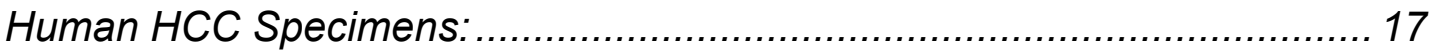

Immunohistochemical Assay for EpCAM in Human Specimens: ................ 17

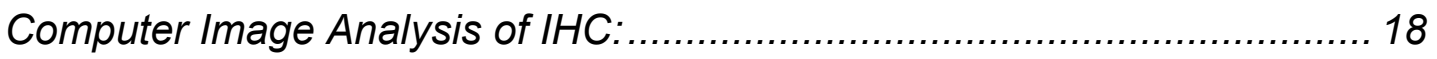

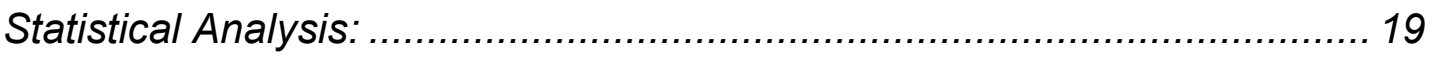

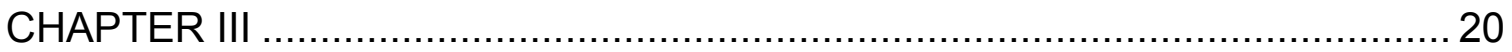

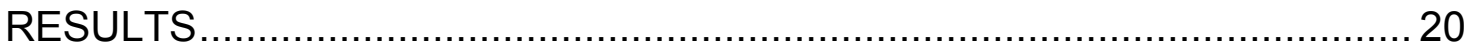

Hepatoma Cells Could Form Anchorage-Independent, Self-Renewing

Spheroids (Spheres) in Serum-Free Culture in vitro: ............................... 20

HCC Spheroids Possessed Resistance Ability to Chemotherapy Drug

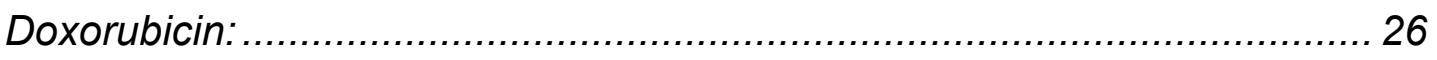

Enriched HCC Spheroids Showed Higher Expressions of Cancer Stem Cells (CSCs) Surface Markers and Functional Markers:................................... 31

Up-Regulation of $\beta$-catenin in HCC CSC Spheroids: ................................. 36

HCC CSC Spheroids Possess Higher Tumorigenic Capability in vivo: ........ 41

Analysis of Human Specimens Found Significant Higher EpCAM

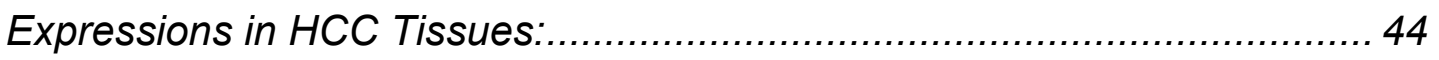

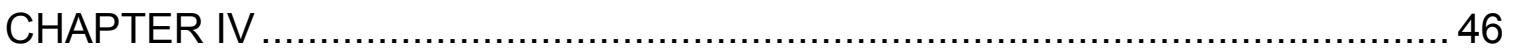

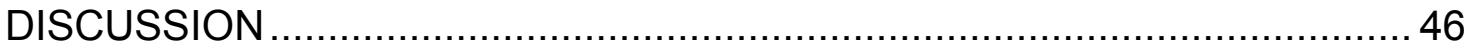

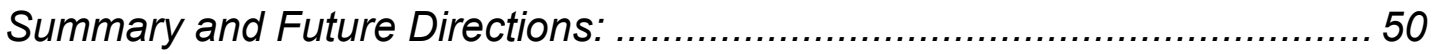

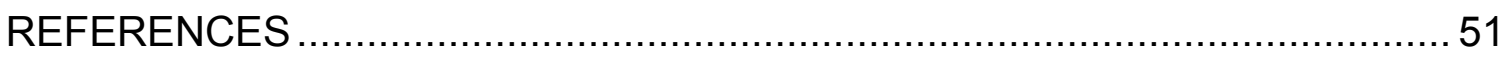

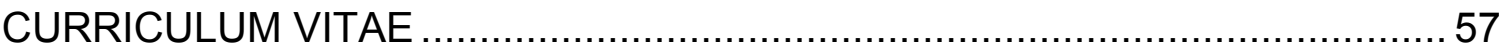




\section{LIST OF FIGURES}

PAGE

Figure 1. Representative Images of Cultured Cells ...........................................23

Figure 2. Hepa1-6 CSC Spheroids Possess Self-Renewal Capability in Serum-Free

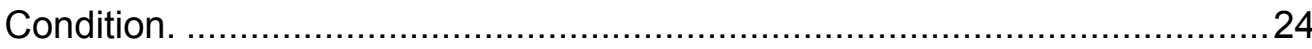

Figure 3. Hepa1-6 Spheroids Retained Proliferative Capability ..................................25

Figure 4. Hepa1-6 Spheroids Exhibit Chemotherapy Resistance for Doxorubicin

(DOX) in Serum-Free Condition. .................................................. 28

Figure 5. Hepa1-6 Spheroids Exhibit Doxorubicin Resistance. ..................................29

Figure 6. Human HepG2 and Hep3B Spheroids Showed Doxorubicin Resistance

Property, Supporting Findings in Mouse Hepa1-6 Cells.............................30

Figure 7. Hepa1-6 Spheroids Showed Increased EpCAM Expression. ......................... 33

Figure 8. Hepa1-6 Spheroids also Showed Increased CD44, CD90 and CD133

Expression, Well Reported CSC Surface Markers. ....................................34

Figure 9. Hepa1-6 Spheroids Showed Increased CSC Functional Markers. .................35

Figure 10. Hepa1-6 Spheroids Showed Increased $\beta$-catenin Levels......................... 38

Figure 11. Hepa1-6 Spheroids Showed Increased Expression of $\beta$-catenin

Downstream Targets.

Figure 12. Higher $\beta$-catenin Levels in Hepa1-6 Spheroids May Be Contributed Via

GSK-3 $\beta$ Activity.

Figure 13. CSC Spheroids Possessed Higher Tumorigenic Capability.........................43

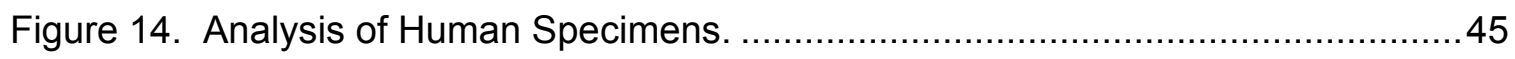




\section{CHAPTER I}

\section{INTRODUCTION}

\section{Hepatocellular Carcinoma (HCC):}

HCC, also referred to as hepatoma, is a type of epithelial cancer in liver, and most common form of liver cancers in adults, usually age 50 or older. HCC is the fifth most common cancer in men and seventh in women worldwide, and accounts for the third major cause of cancer related deaths worldwide [1]. HCC has different growth patterns, and the most common growth pattern seen in the United States is development of HCC secondary to cirrhosis (chronic liver damage), where HCC typically starts as several small cancer nodules at multiple sites in the liver than just a single large tumor. Men are two to four times more likely to develop liver cancer than women. Reports have suggested that $80-90 \%$ of primary liver cancer incidences in the United States are HCC [1, 2]. A 2013 CDC report has suggested that liver cancer related deaths in US men is increasing at rate of $2 \%$ per year despite better success rates in other cancers [1]. 


\section{Risk Factors, Diagnosis and Treatment Modalities:}

Major known risk factors for $\mathrm{HCC}$ are cirrhosis, Hepatitis B virus (HBV) or Hepatitis C virus (HCV) infection, alcoholic liver disease, and non-alcoholic fatty liver disease (NAFLD) [2]. Newly added risk factors are obesity and type-II Diabetes for development of $\mathrm{HCC}[3,4]$. A recent policy statement by American Society of Clinical Oncology (ASCO) reported that obesity will overtake tobacco as the leading cause of cancer in near future [5]. In HCC patients, distribution of these risk factors are highly variable, depending on ethnic groups and geographic regions [6]. Most of these risk factors lead to cirrhosis or its progression, which is present in $80-90 \%$ of HCC patients. According to a study by fattovich et al., the 5 year cumulative risk for $\mathrm{HCC}$ development in cirrhosis patients ranges between $5 \%$ and $30 \%$ globally, $18 \%$ in the United States, depending on cause, ethnic group, and stage of cirrhosis [7]. As a result of the variety of causes and risk factors for HCC, patients show vast diversity in clinical presentation and disease progression, compared to any other solid malignancies.

Treatment options following initial diagnosis is based on staging guidelines. Standard means of assessing prognosis of $\mathrm{HCC}$ patients is Barcelona Clinic Liver Cancer (BCLC) staging system and Child-pugh classification system [8]. Recommended treatment options for HCC patients are surgical resection of tumors, liver transplantation, local ablation, chemotherapy (Doxorubicin), transarterial chemoembolization (TACE) (Doxorubicin), radioembolization, and targeted molecular therapy (Sorafenib). Prognosis and disease free survival is subjective to individual patient and treatment options. Although, we have gained 
scientific advances in diagnosis and treatment modalities, HCC is still considered difficult to treat because of its late presentation, chemotherapy resistance, and high recurrence rate [9].

\section{Cancer Stem Cell (CSC) Model and HCC:}

Our view of carcinogenesis and chemoresistance has changed since the discovery of Cancer Stem

Cells (CSC) or Tumor Initiating Cells (TIC) $[10,11]$

Understanding that tumor development and growth is not only maintained by selection of genetically mutated population

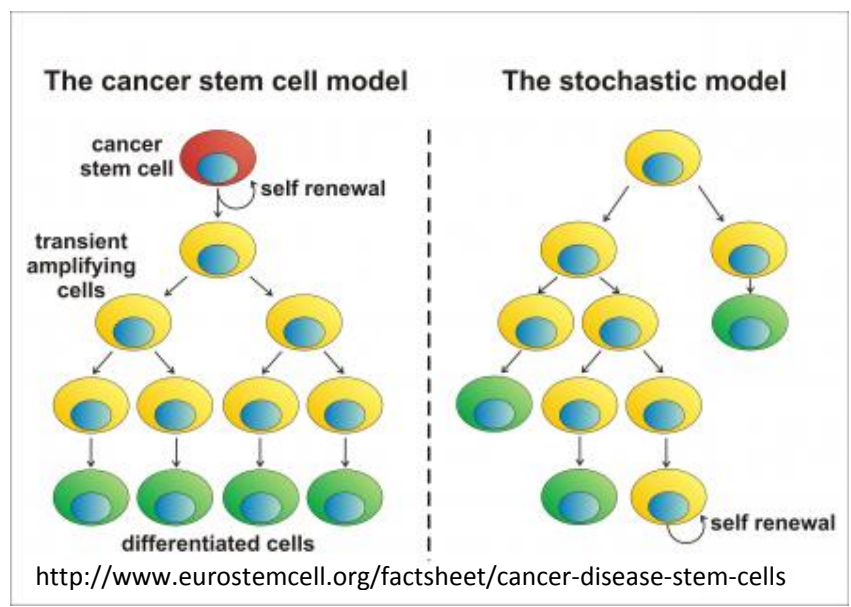

of cells (Stochastic model), but also by the tumor microenvironment which facilitates communication between altered tumor cells and their unaltered neighbors like fibroblasts, endothelial cells, and inflammatory cells [12]. CSCs are a small population of less differentiated cells within the tumor microenvironment which possess stem-cell like properties i.e. self-renewal capability and ability to differentiate into heterogeneous lineages of cancer cells via asymmetric division [10]. CSC model proposes hierarchical organization, where apex CSC retains self-renewal capability with highest tumorigenic potential (Figure-S2), while bottom most differentiated cancer cells lose this important stem-ness property and become less tumorigenic $[10,13]$. Lapidot et al. proposed the CSC hypothesis for the first time in primary human acute 
myeloid leukemias (AMLs) in 1994 [14]. A study on breast cancer by Al-Hajj et al. was the first to report evidence of CSCs in solid tumor [15]. Since then, several studies have been reported presence of CSCs in solid tumors like colon [16], pancreas [17], and liver [18-20]. The first direct evidence to support CSC theory came from lineage-tracing study by Barker et al. in 2007, where they studied tracing of Igr5+ cells in development of small intestine and colon tumors in genetically engineered mice [21]. In 2012, two more groups had published lineage-tracing studies in genetically engineered mouse models [22, 23].

Several groups have studied role of CSCs in HCC and reported their clinical significance $[24,25]$. The CSC tumor model has been proven to show clinical relevance in primary $\mathrm{HCC}$ and $\mathrm{HCC}$ recurrence [25-27]. Haraguchi et al. identified a subset of stem cells, "side population" (SP) cells, in Huh-7 and Hep3B cell lines which highly express multi-drug resistant ABC-transporters [28]. Ma et al. and colleagues have shown that sorted SP cells possess high stemness gene expression and higher tumorigenicity [26, 27]. Using tumorigenicity potential and stemness characteristics as CSC markers, many studies have identified CSCs from human HCC tissues and HCC cell lines expressing the following stem cell markers - EpCAM+, CD90+, CD44+, CD133+, AFP+, OV6+, and ALDH1+ $[25,27,29,30]$. These diverse surface markers on CSCs have been thought to be a result of heterogeneity of tumor microenvironment, and no single surface marker can define HCC CSCs exclusively [31]. In hepatocellular carcinoma, studies have identified EpCAM+ cells in tumors of patients, and showed that these EpCAM+ cells correlate with 
worse prognosis and possess CSC-like properties which showed tumor initiating capabilities in as few as 200 cells in a nude mouse model [18, 30, 32-34]. Recurrence of $\mathrm{HCC}$ after definitive tumor treatment occurs in over $70 \%$ of patients within 14 months of initial treatment. Clinical studies have shown that recurrent $\mathrm{HCC}$ tumors exhibit resistance to chemotherapy treatments and attain aggressive tumor growth [27]. CSCs are resistant to chemotherapeutics and considered as the primary players for tumor relapse and metastasis in HCC [3537]. Importantly, multi-drug resistant transporter ABCG2, a well characterized CSC functional marker, has been implicated for doxorubicin resistance in multiple studies [28, 38-41]. Many recurrent HCC cases have a different biology than the primary index tumor. These recurrent tumors account for most therapeutic failures and eventually result in the death of patients. Molecular mechanism underlying chemotherapy resistance and tumor recurrence in $\mathrm{HCC}$ is not yet clear.

\section{Wnt/ß-catenin Signaling, CSCs, and HCC:}

Canonical Wnt/ß-catenin

signaling pathway regulates several

cellular events including cell

proliferation, and is considered as a

fundamental pathway in stem cell

biology [42]. It is one of the most

extensively studied molecular signaling

pathways in HCC and CSCs [42]. In the

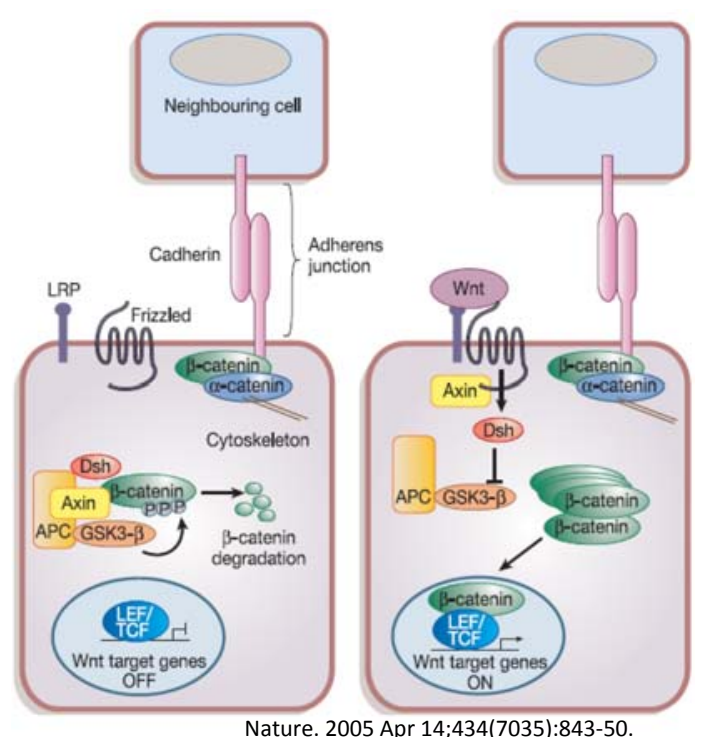


absence of Wnt ligand, $\beta$-catenin is in a complex with APC, Axin, and GSK-3 $\beta$ (termed degradation complex), and gets phosphorylated and targeted for ubiquitin mediated degradation. $\beta$-catenin also exists in a cadherin-bound form and regulates cell-cell adhesion. When Wnt binds to frizzled receptor $(F z)$ and a member of LDL receptor family Lrp5/6 on cell membrane, GSK-3ß (nonphosphorylated, active state) gets phosphorylated at Ser-9 position (inactive state). $\beta$-catenin is uncoupled and gets stabilized following inactivation of GSK$3 \beta$, and the stabilized $\beta$-catenin translocates into the nucleus, where it activates target genes by binding to TCF/LET transcription factors.

Many reports have demonstrated role of $\mathrm{Wnt} / \beta$-catenin signaling in tumorigenic CSCs [42]. EpCAM, one of the important CSC markers, is a target of Wnt/ $\beta$-catenin signaling and inhibiting $W n t / \beta$-catenin signaling has been shown to destroy EpCAM-positive cells $[34,36]$. Studies have reported role of Wnt/ $\beta$ catenin signaling in self-renewal and maintenance of CSCs in HCC $[43,44]$. Also, ABCG2, a functional CSC marker, was suggested to be regulated by $\beta$ catenin in CSCs and contributes to drug resistance [39, 40, 45].

\section{Research Direction and Significance of Our Study:}

Published studies have shown increasing evidence that support the role of CSCs in HCC carcinogenesis, chemotherapy resistance and tumor recurrence, and there is a compelling need to connect and better define these dispersed findings. Importantly, well-reported CSC surface marker EpCAM and CSC functional marker $A B C G 2$ have been reported as targets of $\mathrm{Wnt} / \beta$-catenin 
signaling, and also have been implicated in developing chemotherapy resistance and HCC prognosis. However, origin and activation of CSCs in HCC is not yet been well defined. Our primary goal is to understand the role of Wnt/Bcatenin pathway in HCC CSC activation and development of chemotherapy resistance. In pursuit of this goal, our first task was to enrich, identify and characterize CSCs in our laboratory setting.

In the present thesis work, we have successfully identified HCC cells with CSC-like properties in hepatoma cell lines using in vitro spheroid culture. These CSCs are poorly differentiated, and possess all defined CSC properties i.e. selfrenewal, proliferation, and chemotherapy resistance. Surface markers analysis (EpCAM, CD90, CD44, and CD133) and functional markers analysis (ALDH and Hoechst efflux assays) further confirmed enrichment of CSCs, especially EpCAM+ CSC cells. Preliminary in vivo data in the mouse models support that spheroid forming CSCs show significant higher tumor proliferation rate compared to untreated (non-spheroid forming) HCC cells. Analyzing Wnt/ $/$-catenin pathway components in CSCs showed up-regulation of $\beta$-catenin expression, which is most likely a result of changes in GSK-3 $\beta$ phosphorylation. Analysis of 24 paired human HCC specimens showed higher EpCAM expression compared to adjacent benign tissue. 


\section{CHAPTER II}

\section{MATERIALS AND METHODS}

\section{Cell Lines and Animal Models:}

We have primarily used a mouse hepatoma cell line Hepa1-6 (ATCC CRL1830) for all in vitro experiments. Hepa1-6 cell line is derivative of the BW7756 mouse hepatoma that arose in a C57L mouse. Hepa1-6 cells bear tumor initiating capabilities in an immune competent C57LJ mouse, in orthotopic as well as hind limb models. Use of Hepa1-6 cells with C57LJ mouse equipped us to establish the best $\mathrm{HCC}$ orthotopic model possible resembling clinical HCC closely in our lab.

We confirmed our findings in human hepatoma cell lines, Hep3B (ATCC HB-8064) and HepG2 (ATCC HB-8065). Our lab has an established HCC orthotopic animal model using Hep3B cells in BLAB/C nude mice.

\section{Cell Culture and Spheroid Formation:}

Hepa1-6 and Hep3B cells were grown in DMEM (MediaTech, Corning, Cat \# 10-013-CV) with 4.5\% Glucose, supplemented with 10\% FBS (Sigma, Cat \# F2442), $100 \mathrm{IU} / \mathrm{mL}$ Penicillin, $100 \mu \mathrm{g} / \mathrm{mL}$ Streptomycin, $0.25 \mu \mathrm{g} / \mathrm{mL}$ Amphotericin 
(Antibiotic and Antimycotic, MediaTech Corning, Cat \# 30-004-Cl), $10 \mu \mathrm{g} / \mathrm{mL}$ Tylosin (Antimycotic, Sigma, Cat \# T3397). HepG2 cells were grown in Minimum Essential Media (MEM, Gibco, Cat \# 11095-080), supplemented with 10\% FBS (Sigma, Cat \# F2442), Non Essential Amino Acids (Gibco, Cat \# 11140-050), Sodium Pyruvate (Gibco, Cat \# 11360-070), 100 IU/mL Penicillin, 100 ug/mL Streptomycin, $0.25 \mu \mathrm{g} / \mathrm{mL}$ Amphotericin (Antibiotic and Antimycotic, MediaTech Corning, Cat \# 30-004-Cl), $10 \mu \mathrm{g} / \mathrm{mL}$ Tylosin (Antimycotic, Sigma, Cat \# T3397).

For in vitro enrichment of Cancer Stem Cells (CSCs), we employed a widely used and accepted spheroid formation assay. Hepa1-6, HepG2, and Hep3B cells were grown in a serum-free condition (SF Group) in DMEM/F12 (1:1) media (SIGMA, Cat \# D6434), supplemented with 2 mM L-Glutamine (SIGMA, Cat \# G7513), 20 ng/mL recombinant human Epidermal Growth Factor (EGF, Sigma, Cat \# E9644 ), and $10 \mathrm{ng} / \mathrm{mL}$ recombinant human basic Fibroblast Growth Factor (bFGF, Sigma, Cat \# F0291 ), 100 IU/mL Penicillin, 100 ug/mL Streptomycin, $0.25 \mu \mathrm{g} / \mathrm{mL}$ Amphotericin (Antibiotic and Antimycotic, MediaTech Corning, Cat \# 30-004-Cl), 10 gg/mL Tylosin (Antimycotic, Sigma, Cat \# T3397).

\section{Self-Renewal Assay:}

Hepa1-6 cells were seeded in serum-free (SF) media at a density of 2000 cells/well in 6-well plate, and incubated for 4 days to allow the development of speroids. After confirming formation of spheroids under the microscope, these spheroid population of cells were collected in $15 \mathrm{~mL}$ centrifuge tube, treated with trypsin-EDTA for 4 minutes, and prepared single-cell suspension with 500 
cells/mL density with SF media. Seed single cell suspension at 2 uL/well in 96 well plate. Mark the wells with one or two cells. Add $150 \mathrm{uL} \mathrm{SF}$ media in each marked well and monitor for 20 days. Images were taken on a daily basis to track progress.

\section{Cell Proliferation Assay:}

Cell proliferation was measured using the MTT assay (3-(4,5-dimthylthiazol-2-yl)-2,5 diphenyltetrazolium bromide) in a 96 well format. Hepa1-6 cells were seeded in triplicates at a density of 3000 cells/well in complete media (control group) or serum-free media (SF group) and grown overnight. A separate plate was prepared for each time-point $(0,24,48,72$, and 96 hours). After appropriate incubation period, MTT was added in each well at the final concentration of $0.5 \mathrm{mg} / \mathrm{mL}$, and plate was incubated for 3 hours at $37^{\circ} \mathrm{C}$ in $\mathrm{CO}_{2}$ incubator. After MTT incubation, media was removed from each well and $100 \mathrm{uL}$ DMSO was added to dissolve formazon crystals which generate violet color. Absorbance was measured with plate reader at $540 \mathrm{~nm}$ with appropriate controls in each plate. For purpose of calculation, we considered the shorter incubation time MTT reading (overnight) as 0 hour and set it as control for the subsequent time points.

\section{Doxorubicin (Adriamycin) Resistance Assay:}

Hepatoma cells (Hepa1-6, HepG2, and Hep3B) were seeded at a density of 5000 cells/well in a 96 well plate in triplicates, with one set of control group (complete media) and two sets of spheroids group (serum-free media). Separate 
96 well plates were seeded for different time points (24, 48, 72 and 96 hours) simultaneously on the day of seeding. After 24 hours, serum-free media is replaced with complete media in one of the two sets of spheroids group (termed as SFR, reserum) and incubated for another 24 hours. On the day 3, media is replaced with complete or serum-free media containing different concentrations of Doxorubicin (0.05 $\mu \mathrm{M}, 0.5 \mu \mathrm{M}$ (clinical), and $5 \mu \mathrm{M}$ (10x clinical)) (SIGMA, Cat \# D1515). MTT assay was performed at $24,48,72$, and 96 hours after initiating DOX treatments as described in the cell proliferation assay. Each plate and group had appropriate untreated control in triplicates, and corresponding data for untreated group was considered as 1 i.e. $100 \%$ viability. DOX treated cells were normalized to their corresponding untreated controls on the same plate, compared and analyzed.

\section{Flow-Cytometry Analysis:}

Hepa1-6 control or 7 day spheroid cells grown in $100 \mathrm{~mm}$ discs were collected by gentle cell scraping. Collected cells were passed through 50 micron strainer 5 times to remove cell clumps, followed by repeate pipetting for $10-20$ times to obtain closest single cell suspension. Use of trypsin was avoided to preserve integrity of surface receptors to its best. Cell numbers were counted and single cell suspension was verified using a Hemocytometer. Each sample was transferred to a $15 \mathrm{~mL}$ tube and centrifuged for 5 minutes at $300 \mathrm{RCF}$ to obtain cell pellet. Cell pellets were washed 2 times with $2 \%$ BSA/PBS. Pellets were resuspended in $100 \mathrm{uL} 2 \% \mathrm{BSA} / \mathrm{PBS}$ and transferred into $1.5 \mathrm{~mL}$ microfuge tubes. Corresponding unstained and single stained controls were seperated for 
each sample, $10^{6}$ cells/100 uL. FITC, APC or PE conjugated primary antibodies were added in $100 \mathrm{uL}$ of cell suspension as per datasheet or in-house optimized dilution (1:100 for most experiments and antibodies). Samples are gently vortexed and incuabted in the dark at $4{ }^{\circ} \mathrm{C}$ for 1 hour. After incubation, cells were washed once with $1 \mathrm{~mL} 2 \% \mathrm{BSA} / \mathrm{PBS}$, resuspended in $500 \mathrm{uL} 2 \%$ BSA/PBS, transferred into labeled flow-tubes, and stored in the dark on ice until analysis were performed. Data were recorded on BD FACSCanto. For analysis, after correct set-up of voltages for FSC and SSC, live cells were gated to exclude dead cells and cell debris. Required compensations were performed for dual FITC and PE staining experiments. In majority of our experiments, we chose FITC and APC (emission spectra don't overlap). Data analysis was performed either by FACS Diva or FlowJo software suites.

\section{Immunocytochemistry (ICC) Staining:}

Hepa1-6 control or spheroid cells were grown in 8 well Nunc ${ }^{\text {TM }}$ Lab-Tek-II chamber slide (Thermo scientific, Cat \# 154534) for 7 days (seeded at 100 cells/well to avoid overgrowth at the end of 7 days). Media was changed on the $4^{\text {th }}$ day to ensure viability. Cells were fixed with $4 \%$ PFA for 30 minutes (or $70 \%$ ethanol overnight). Fixed cells were washed 2 times for 15 minutes with PBS-T, and blocked with $10 \%$ BSA in PBS for 20 minutes. Blocked cells were washed again for 2 times for 15 minutes with PBS-T and incubated with 100 uL primary FITC conjugated antibodies at room temprature for 2 hours (EpCAM, CD90, CD133, 1:100 dilution in 10\% FBS in PBS-T). Following antibody incubation, cells were given 3 time 10 minute PBS-T washes and stained for nuclear staining 
with DAPI (1:1000 dilution). After DAPI staining, cells were given 2 time 10 minute PBS-T washes. Plastic chambers were removed from each Lab-Tek slides as per manufacterur's instructions, using the tools provided and exposed glassslide surface with cells were sealed with coverslip using $5-10 \%$ glycerin. The slides were examined using Olympus $1 \times 51$ microscope at $20 x$ magnification using the Olympus DP72 digital camera via the cellSens Dimention imaging system (Olympus, Pittsburgh, PA) with FITC, DAPI and brightfield settings. Digital images were taken, stored and then overlapped using software tool to analyzed for FITC positive cells in each experiments.

\section{Aldefluor Assay for ALDH Activity:}

Aldefluor activity was assayed in Hepa1-6 control and spheroid cells using Aldefluor kit according to the manufacturer's instructions (Stemcell technologies, Canada). Briefly, $3 \mathrm{~mL}$ of cell suspension was prepared in DMEM without serum at $10^{6}$ cells $/ \mathrm{mL}$ final dilution. These cells were centrifuged at $250 \mathrm{RCF}$ for 5 minutes, and pelleted cells were resuspended in $3 \mathrm{~mL}$ of Aldefluor buffer on ice. To get the fluorescence product, we added $45 \mathrm{uL}$ of Aldefluore substrate into 3 $\mathrm{mL}$ of the each of the cell suspension samples on ice. Immediately after mixing, 1 $\mathrm{mL}$ was transferred into a new tube containing $30 \mathrm{uL}$ ALDH1 inhibitor diethylaminobenzaldehyde (DEAB), and later used as an inhibitor control (negative control). Test samples and negative controls were incubated at $37^{\circ} \mathrm{C}$ for 45 minutes, mixed every 10 minutes. Then, cells were cenrifuged at $250 \mathrm{RCF}$ for 5 minutes, resuspended in Aldefluore buffer and incubated on ice for 1 hour. 
Data were recorded on BD FACSCanto at FITC channel with 488 excitation laser.

\section{Hoechst 33342 Efflux Assay:}

After 7 days in culture, Hepa1-6 Control or spheroid cells were harvested in $15 \mathrm{~mL}$ centrifuge tubes. $5 \mathrm{~mL}$ cell suspension with $10^{6}$ cells $/ \mathrm{mL}$ was prepared for each sample, centrifuged at $250 \mathrm{RCF}$ for 5 minutes, washed two times and resuspended in 2\%FBS in PBS. Hoechst 33342 (Life technologeis, Cat \# H1399) dye was added to $5 \mathrm{mg} / \mathrm{mL}$ final concentration in $2 \%$ FBS in PBS and cells were incubated for 90 minutes at $37^{\circ} \mathrm{C}$. Cells were then incubated on ice for 10 minutes, and followed by a single wash of ice cold 1X PBS. These cells were immediately mounted on glass slides and analyzed within 1 hour on a fluorescence microscope with UV excitation settings. It is imperative that cells were viable during the steps of the assay. Hoechst 33342 dye stains the nuclear compartment and is visible at $355 \mathrm{~nm}$ excitation (blue color) using the common DAPI filter. Cells with dye exclusion property were identified by comparing/overlaping with images obtained under brightfield settings.

\section{Protein Extraction and Western Blot:}

After treating cells with respective media and/or regulators for desired time, media was aspirated from the culture and cells were washed two times with 1X PBS. Cells were lysed by adding SDS lysis buffer (supplemented with protease and phophatase inhibitors, Thermo scientific, Cat \# 78443) directly into wells (100 uL per well of 6 -well plate or $500 \mathrm{uL}$ per $100 \mathrm{~mm}$ plate). For spheroids 
group (non-adharent cells), cells were collected by gentle scraping and pipetted into $15 \mathrm{~mL}$ centrifuge tube. Culture media was removed by centrifugation for 5 mins at $150 \mathrm{RCF}$ to collect cells followed by two time 1x PBS washes to remove all media traces. Lysis buffer was then added into the tube according to pelleted packed cell volume (100 uL lysis buffer for each 20 uL packed cell volume). Cells were transfered to $1.5 \mathrm{~mL}$ microfuge tube and sonicated for $10-15$ seconds on ice. After 30 minutes incubation on ice, lysates were centrifuged for 30 minutes at $14,000 \mathrm{RCF}$ at $4{ }^{\circ} \mathrm{C}$. Supernatant containing total cellular protein was collected carefully and transfered to new labeled $1.5 \mathrm{~mL}$ microfuge tube. Purified protein samples were stored at $-80^{\circ} \mathrm{C}$ untill further use. For cytoplasmic and nuclear fractionation, we used a commercially available kit (Pierce, ThermoFisher, Cat \# 78833). Fractionation was performed as per manufacturer's protocol. Extracted protein were stored at $-80^{\circ} \mathrm{C}$ untill further use.

Extracted protein was quantified using the Bradford assay (Biorad, Cat \# $500-0006)$ in a 96 well plate format and readings were performed at $620 \mathrm{~nm}$ using the ELISA reader (MultiSKAN MCC/340, Thermo Scientific).

Equal protein (20-50 $\mu \mathrm{g}$ each) were loaded for SDS-PAGE electrophoresis on $8 \%$ gel. Protein samples were seperated by SDS-PAGE and then electrotransferred onto nitrocellulose membrane (Amersham, GE) . Following electrotransfer, the membane was blocked in $5 \%$ non-fat milk for 1 hour at room temprature. The membrane were incubated in primary antibody overnight at their best working concentration (1:1000 or 1:2000 final dilution). Next day, the membrane with overnight incubated primary antibodies were washed 3 times 
with TBST for 7 minutes each. Next, the membrane was incubated for 1 hour in secondary HRP conjugated-Anti-Mouse IgG (Cell Signaling, Cat \# 7076; OR Santacruz Biotech, Cat \# sc-2005) or secondary HRP conjugated-Anti-Rabbit IgG (Call Signaling, Cat \# 7074; OR Santacruz Biotech, Cat \# sc-2004 ). Secondary antibodies were diluted either 1:2000 or 1:4000 as per experimental requirement. Secondary antibody blot was washed 3 times by TBST, followed by 1 wash of TBS and incubated in dark for 1 minute in Westen Blot Luminol Reagent (Santacruz Biotech, Cat \# sc-2048). Chemiluminescence signals were detected in the darkroom using x-ray films. Densitometry analysis were conducted using ImageJ software (NIH).

Primary antibodies: $\beta$-Catenin (SantaCruz Biotech, Cat \# sc-7963), $\beta$ actin (SantaCruz Biotech, Cat \# sc-81178) , GAPDH (SantaCruz Biotech, Cat \# sc-365062), GSK3ß (Cell Signaling, Cat \# 9832), phospho-GSK3ß (Ser-9) (Cell Signaling, Cat \# 5558), ABCG2 (Cell Signaling, Cat \# 4477), Cyclin-D1 (Cell Signalling, Cat \# 2978), TCF-1 (Cell Signaling, Cat \# 2203), C-MYC (Cell Signaling, Cat \# 5605).

\section{Animal Experiments:}

All experimental procedures were approved by the Institutional Animal Care and Use Committee (IACUC) at University of Louisville (UofL). IACUC at UofL is certified by American Association for Accreditation of Laboratory Animal Care. All mice were housed in the University of Louisville Research Resources Center at $22{ }^{\circ} \mathrm{C}$ with $12-\mathrm{h}$ light/dark cycle with free access to food and water. 
In vivo experiments using Hepa1-6 cell-lines were performed in 8 week old C57L/J mice (All male). Each group had 3 animals. For orthotopic inoculation, 1 $\times 10^{7}$ Hepa1-6 control or spheroid forming cells (serum free group -7 day treatment), were injected into liver of the animal. Post injection, mice were monitored for two weeks and then euthanized. Animal weight, liver weight, tumor weight, and tumor size were recorded for each animal. In vivo study using human Hep3B cells was performed in the same way in 8 week old orthotopic BLAB/C nude mouse model.

\section{Human HCC Specimens:}

This study was approved by the Institutional Review Board for Human Study at University of Louisville. The study samples were retrospectively collected from 24 patients who had undergone liver resection for hepatocellular carcinoma between 2002 and 2013. 24 subjects, 13 male (54.2\%) and 11 female $(45.8 \%)$ with a median age of 67 , ranging from 41 to 84 years old, had a clinical diagnosis of hepatocellular carcinoma and underwent liver resection. The control samples consisted of the same 24 patients' normal adjacent tissue that were within the resected liver specimen.

\section{Immunohistochemical Assay for EpCAM in Human Specimens:}

EpCAM protein expression were determined by using an immunohistochemical assay. Staining was carried out on the paraffin-embedded tissues using the DAKO EnVisionTM+System kit (DAKO Corporation, Carpinteria, CA) according to the manufacturer's instructions. The sections were 
deparaffinized and hydrated, then the slides were washed with TRIS buffer. Peroxidase blocking was performed for 5 minutes. After rewashing, the slides were incubated with EpCAM antibody (1:100) (SantaCruz Biotechnology Inc, CA) for 30 minutes at room temperature. The slides were rinsed and the specimens were incubated with the labeled polymer for 30 minutes at room temperature. Then, the chromogenic substrate diaminobenzidine was added as a visualization reagent. Finally, the slides were counterstained with methyl green for EpCAM. A negative control was included in each run.

\section{Computer Image Analysis of IHC:}

A computer image analysis was performed to quantify the expression of EpCAM in the 24 samples diagnosed with HCC, and in the 24 samples of adjacent normal liver (AD). The imaging fields were chosen randomly from various section levels to ensure objectivity of sampling. Five imaging fields were scanned for each specimen sample. All digital images were acquired with the Olympus i $\times 51$ microscope at 40x magnification using the Olympus DP72 digital camera via the cellSens Dimention imaging system (Olympus, Pittsburgh, PA) and stored as JPG data files with fixed resolutions of 200 pixels/inch. The acquired color images from the immunohistochemical staining were defined at a standard threshold according to the software specification. The computer program then quantified the threshold area represented by color images. EpCAM protein expression was defined by the percentages of threshold area in acquired color images. 


\section{Statistical Analysis:}

Data are presented as mean \pm S.D. ( $n \geq 3$ per group). Comparisons were performed by two-tail student's t-test with equal variance (Microsoft Excel 2013). For analysis of human specimens, analysis of variance (ANOVA) was used to determine the differences in EpCAM expression between paired samples. Results with $p \leq 0.05$ were considered statistical significant. 


\title{
CHAPTER III
}

\author{
RESULTS
}

\section{Hepatoma Cells Could Form Anchorage-Independent, Self-Renewing}

\section{Spheroids (Spheres) in Serum-Free Culture in vitro:}

Serum-free conditions enriched in growth factors allow cells to grow in anchorage-independent manner, and is a well-documented and standard method for maintaining undifferentiated cells [46]. This technique is widely adapted for CSC studies in breast cancer [47] and glioblastoma [48]. Soon after, this technique was accepted and used in many other solid tumor malignancies including hepatocellular carcinoma [27, 49]. Also known as spheroid formation (sphere formation) culture, this is not only a CSC property, but also serves as a valuable tool to enrich CSC-like cells in vitro.

To enrich HCC CSCs from hepatoma cell lines in vitro, we employed serum-free conditions using DMEM/F-12 (1:1) media supplemented with recombinant human Epidermal Growth Factor (EGF) and basic Fibroblast Growth Factor (bFGF). We evaluated spheroids for CSC properties. We found that all three hepatoma cell lines (Hepa1-6, HepG2, Hep3B) successfully formed spheroids in serum-free conditions (Figure-1). 
Self-renewal capability is the most fundamental property of CSCs and proposed as the primary mechanism responsible for maintaining undifferentiated cells with CSC like properties in tumors [50]. We have primarily characterized Hepa1-6 spheroids. To test if enriched Hepa1-6 spheroids possess self-renewal capability, we performed two separate experiments. In the first experiment, we tested if spheroid cells can be serially passed from one generation to the next without dying or losing spheroid forming capability. The rationale behind this experiment is that well differentiated cells cannot survive in serum-free stress conditions optimized for anchorage independent growth, while only cells with stem-like properties are able to maintain themselves and propagate. Hepa1-6 spheroids were serially passaged for more than 10 generations in serum-free conditions, indicating their self-renewal capability (data not shown).

In the second experiment, we confirmed self-renewal capability of CSC like cells by means of more quantitative "self-renewal assay". Hepa1-6 spheroid cells were seeded in 96 well plates (single cell/well) and monitored for their growth pattern daily for 20 days (Figure-2). In this condition, cells can have one of the three fates: 1) self-renewal (spheroid formation), 2) differentiation (adherent phenotype), 3) quiescence (stays as a single cell). Approximately, $24 \%$ Hepa1-6 cells showed self-renewal capability by forming spheroids. These growing spheroids (Figure-2.A \& C) also expressed EpCAM (CSC marker), further supporting CSC like-properties of spheroids. Around $51 \%$ cells stayed in the quiescence state, while about $25 \%$ cells lost their stem-ness and proceeded to differentiation (Figure-2.D). 
We also performed an MTT assay to quantitate cell proliferation rates in Hepa1-6 control and spheroid cells. We have found that Hepa1-6 spheroids retained proliferative capability but growth rate is significantly slower than parental control cells (Figure-3). 


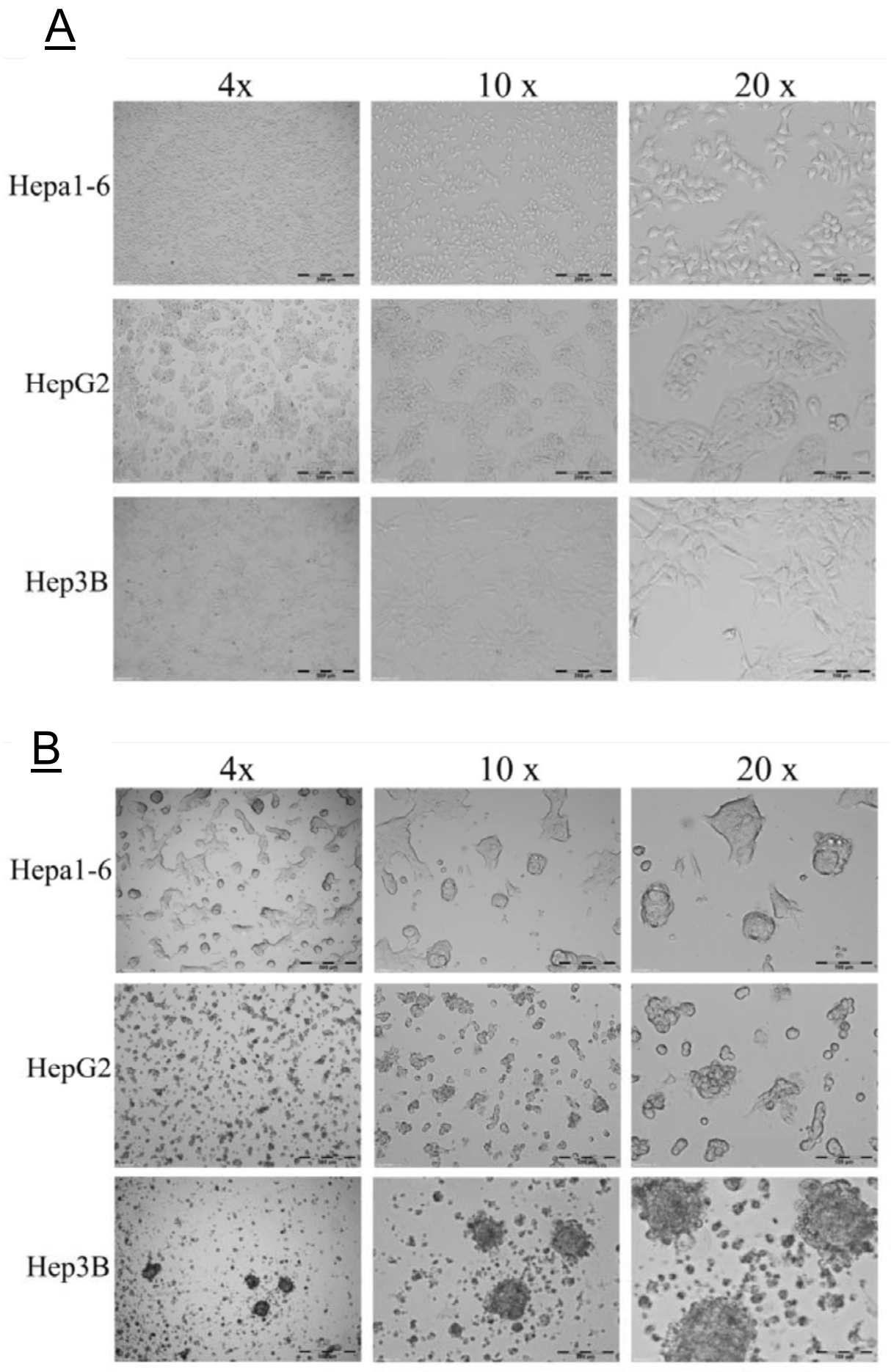

Figure 1. Representative Images of Cultured Cells. Bright field microscope images. (A) Control hepatoma cells and (B) CSC Spheroids (Serum-free /SF group) in Hepa1-6, HepG2, and Hep3B cell lines. 4x (Bar =500 $\mu \mathrm{m}), 10 \times(B a r=$ $200 \mu \mathrm{m})$, and 20x (Bar $=100 \mu \mathrm{m})$. 

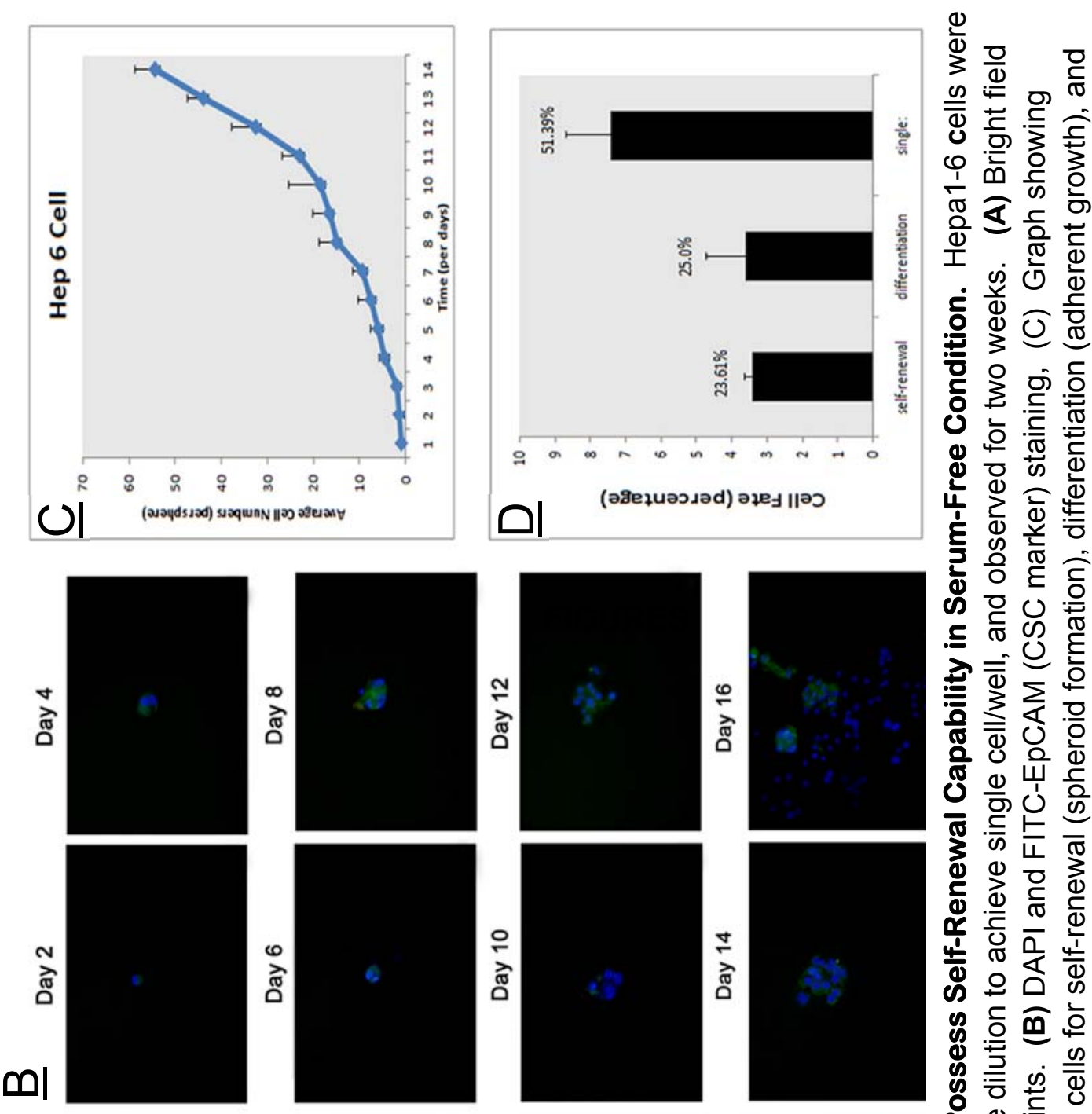

О ํํำ め 으 . 응 잉 仓 ชู ญ ய 응

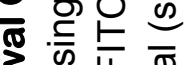
उ ఏ 崩 崩 ஸ 드 \& \& ๑ @ 등 II
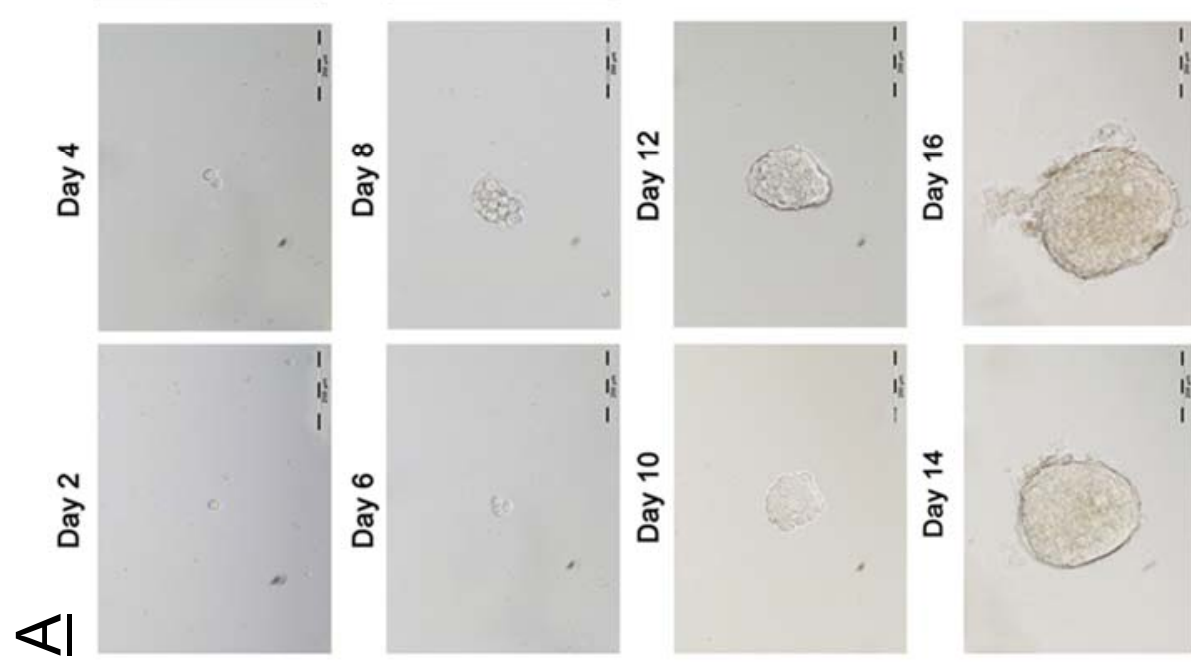

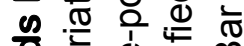
응 응 잉 을 흘 잉 응 등 응 ஸำ 은 \% 曹 $\circlearrowleft \stackrel{\Phi}{ \pm}$ 䒕 0 을 চ $\overline{\overline{0}}$ 宁 은 전 잉 을 v . 응 잉 닌 


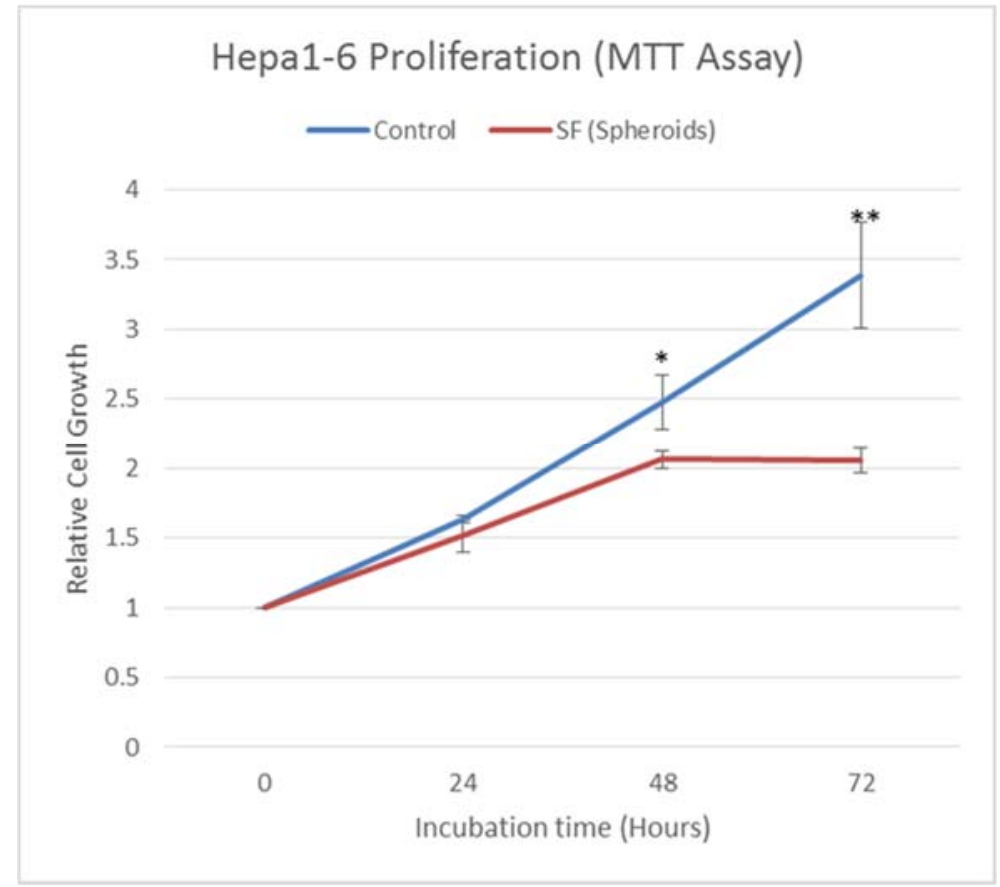

\begin{tabular}{|c|c|c|c|c|}
\hline \multicolumn{5}{|c|}{ MTT Assay - Hepa1-6 proliferation } \\
\hline & \multicolumn{4}{|c|}{ Incubation time (hours) } \\
\hline & 0 & 24 & 48 & 72 \\
\hline Control & 1 & $1.63 \pm 0.02$ & $2.47 \pm 0.19$ & $3.39 \pm 0.38$ \\
\hline SF (Spheroids) & 1 & $1.51 \pm 0.12$ & $2.06 \pm 0.06$ & $2.05 \pm 0.09$ \\
\hline \multirow[t]{2}{*}{ P Value } & NA & 0.167 & 0.025 & 0.004 \\
\hline & NA & NS $(p>0.05)$ & $*(p<0.05)$ & $* *(p<0.005)$ \\
\hline \multicolumn{5}{|c|}{$\mathrm{N}=3$ Experiments } \\
\hline \multicolumn{2}{|c|}{$\begin{array}{l}\text { Values shown as "Mean } \pm \\
\text { S.D." }\end{array}$} & & & \\
\hline
\end{tabular}

Figure 3. Hepa1-6 Spheroids Retained Proliferative Capability. MTT Assay was performed in 96 well plate, with seeding 3000 cells/well in triplicates. CSC spheroids retained proliferative capabilities in serum-free media, but exhibit slower growth rate compared to control group cells (complete media with serum). $n=3$ independent experiments. Values shown in "Mean \pm S.D". 
HCC Spheroids Possessed Resistance Ability to Chemotherapy Drug

\section{Doxorubicin:}

Resistance to chemotherapeutics is another important characteristic of CSCs, and is believed to play a significant role in HCC carcinogenesis and recurrence [24]. Currently, doxorubicin (Adriamycin, DOX) is a first line drug used for HCC treatment in clinics [2].

We studied Hepa1-6 spheroids for their DOX resistance property with MTT assay as described in materials and methods. For in vitro experiments, we selected a clinical relevant dose $(0.5 \mu \mathrm{M})$ as characterized in early pharmacokinetic studies in patients and widely employed by other groups for DOX studies [51]. We have also tested $1 / 10(0.1 \mathrm{x}, 0.05 \mu \mathrm{M})$ and 10 times $(10 \mathrm{x}$, $5 \mu \mathrm{M})$ doses for characterization. Time dependent dose response curves have demonstrated that Hepa1-6 CSC spheroids were sensitive to DOX at early time points, but developed resistance 48 hours post DOX treatment at both subclinical and clinical doses (Figure-4). We found that for the $10 \mathrm{x}$ dose, $5 \mu \mathrm{M}$, there were a fraction of cells that retained higher viability after 72 hours.

When we further analyzed our data by plotting log (DOX dose) v/s viability at 96 hour time-point, we found that Hepa1-6 spheroids required 2 times more DOX compared to control cells to eradicate $50 \%$ viable cells (Figure-5.A). Hepa1-6 spheroids were seen to have significantly increased chemotherapy resistance for doxorubicin at not only physiologically relevant dose of $0.5 \mu \mathrm{M}$ but also to 10 fold dose increase $(5 \mu \mathrm{M})(\mathrm{p}<0.005)$ (Figure-5.B). 
We have also investigated HepG2 and Hep3B spheroids for their DOX resistance properties. After 96 hours of treatment, both HepG2 and Hep3B CSC spheroids showed significant higher resistance for DOX compared to control cells at clinical dose of $0.5 \mu \mathrm{M}(\mathrm{p}<0.05)($ Figure-6). These data support our results found in Hepa1-6 spheroids. 

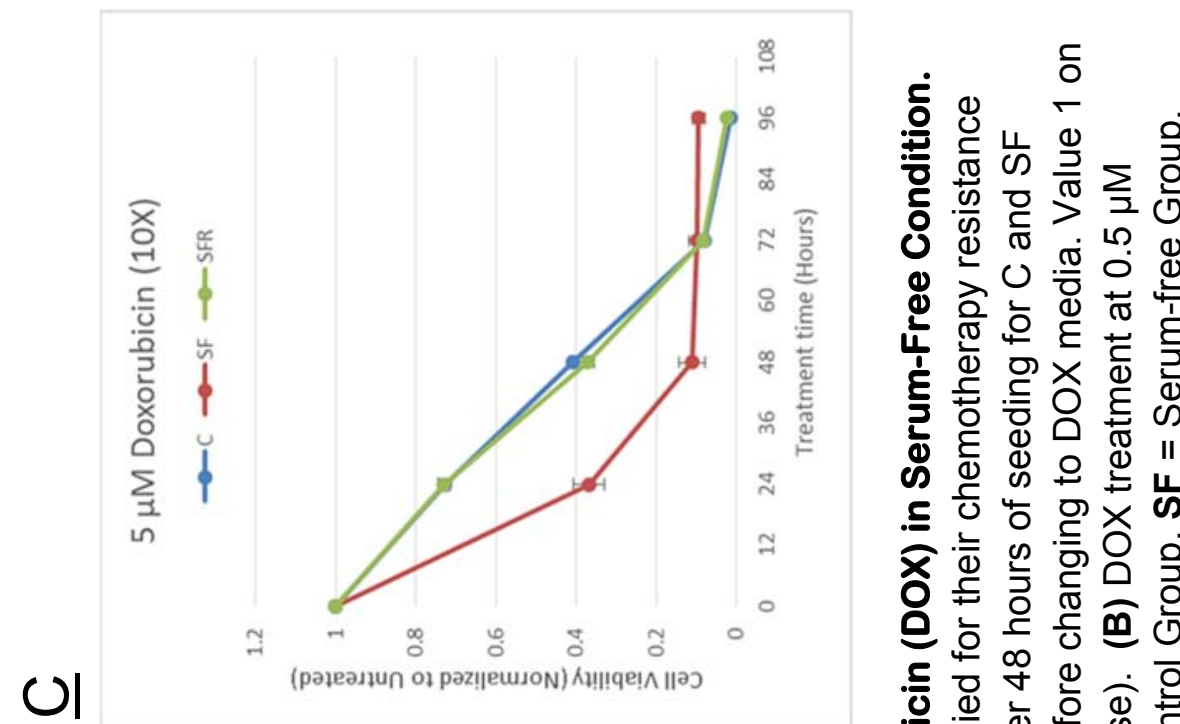

.ミ过

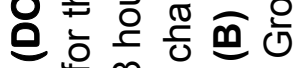

OI

. 등 원

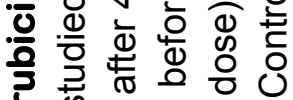

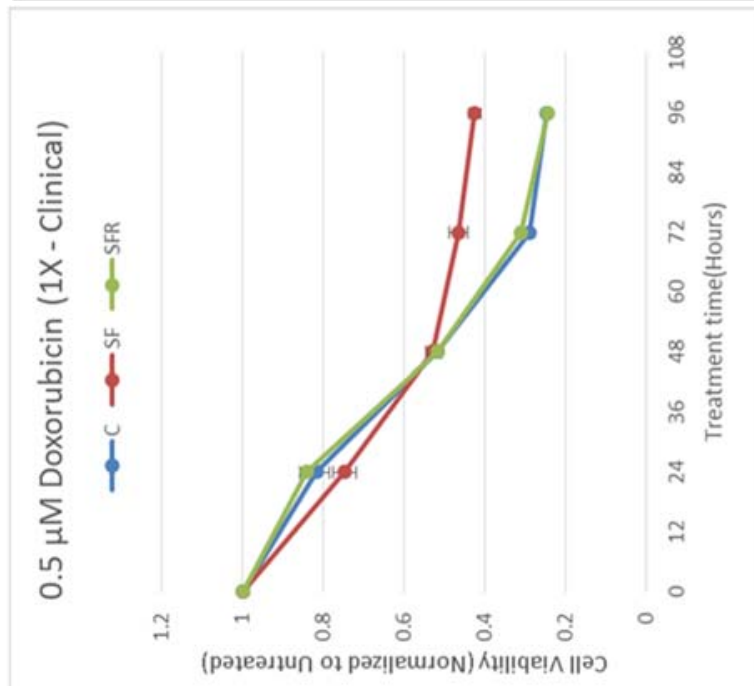

m)

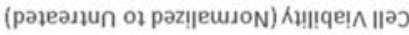

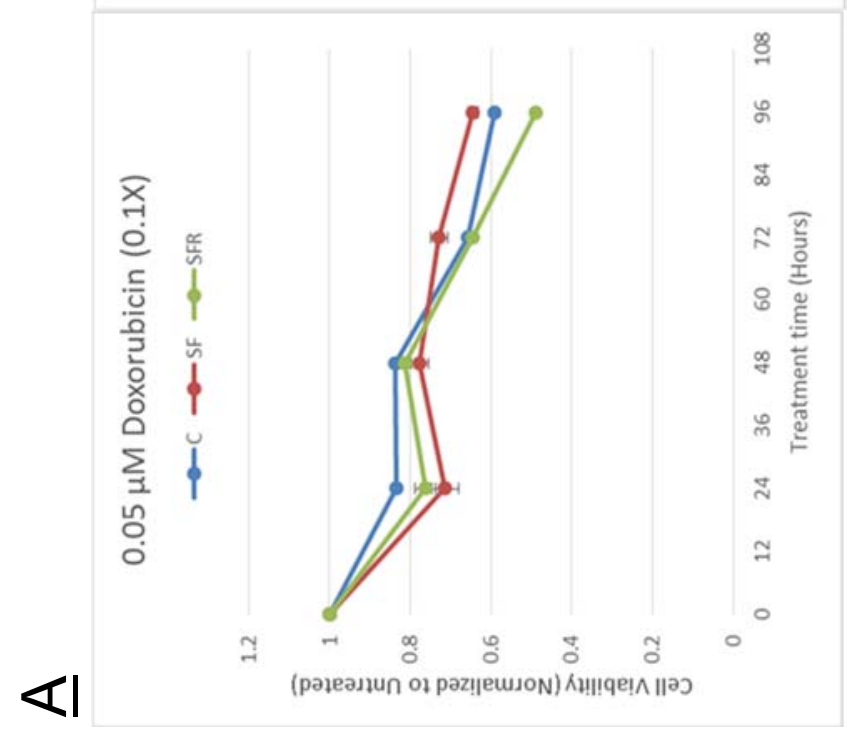

它

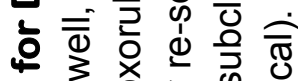

ญ के

잉

类 0 응

.

幽

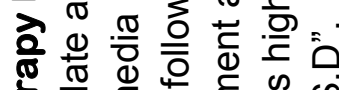

ॠ

㝴市

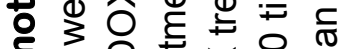

ஸ

ט. $\cong$

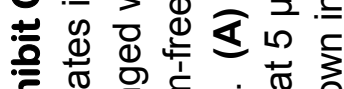

产

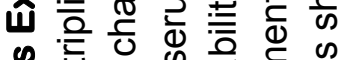

की 0 क त ह

응.$\frac{\pi}{0}$ ते

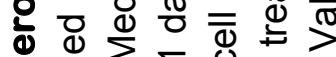

รัญ

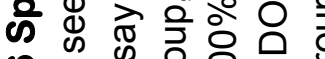

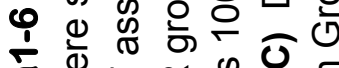

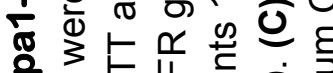

产品

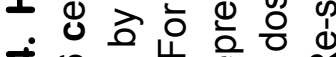

ఖ

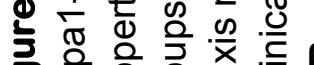

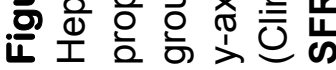



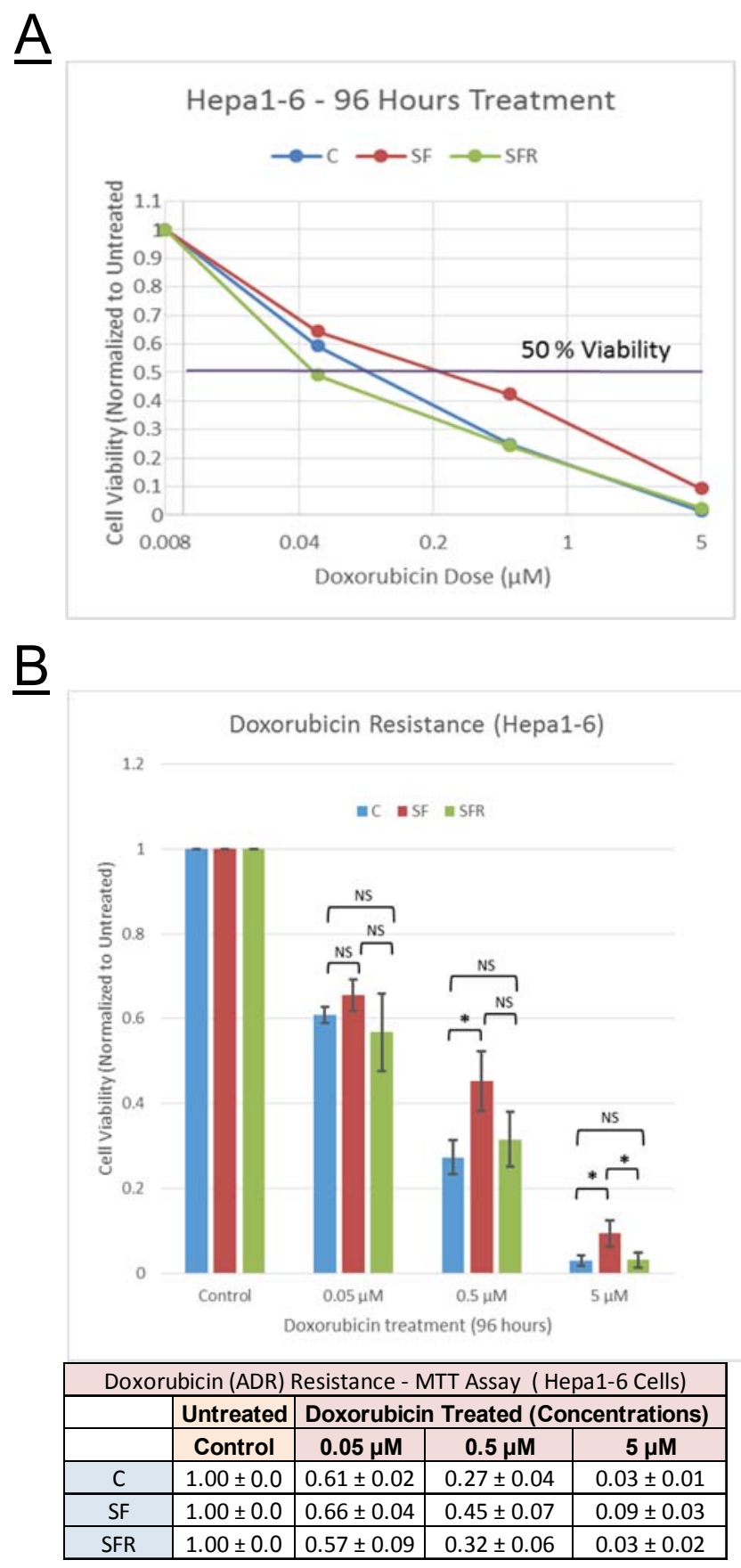

Figure 5. Hepa1-6 Spheroids Exhibit Doxorubicin Resistance. Value 1 on y-axis represents $100 \%$ cell viability. (A) Dose dependent response curve (Log [Dox] v/s Cell viability) after 96 hours of Doxorubicin treatment. Hepa1-6 spheroids required increased Doxorubicin dose (2 times higher than C, and 4 times higher than SFR) to eradicate $50 \%$ cells. (B) Hepa1-6 spheroids (SF) are more resistant to Doxorubicin compared to control(C). $n=3$ independent experiments, values shown in "Mean \pm S.D", * $(p<0.05)$, NS=No significance $(p>0.05)$. $\mathbf{C}=$ Control group, $\mathbf{S F}=$ Serum-free group, $\mathbf{S F R}=$ Reserum group. 


\section{FIGURES}

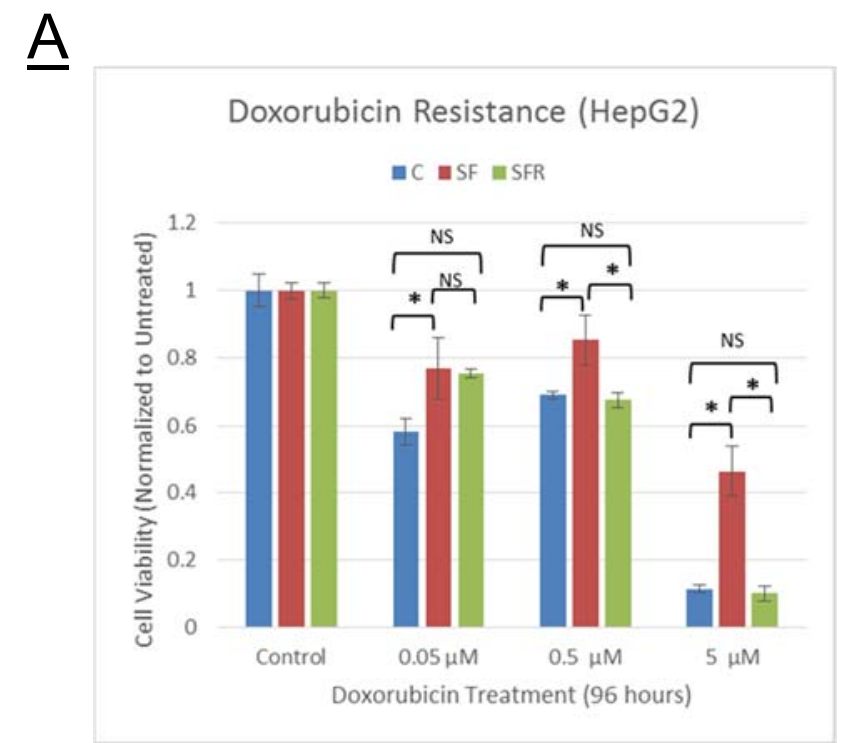

$\underline{B}$

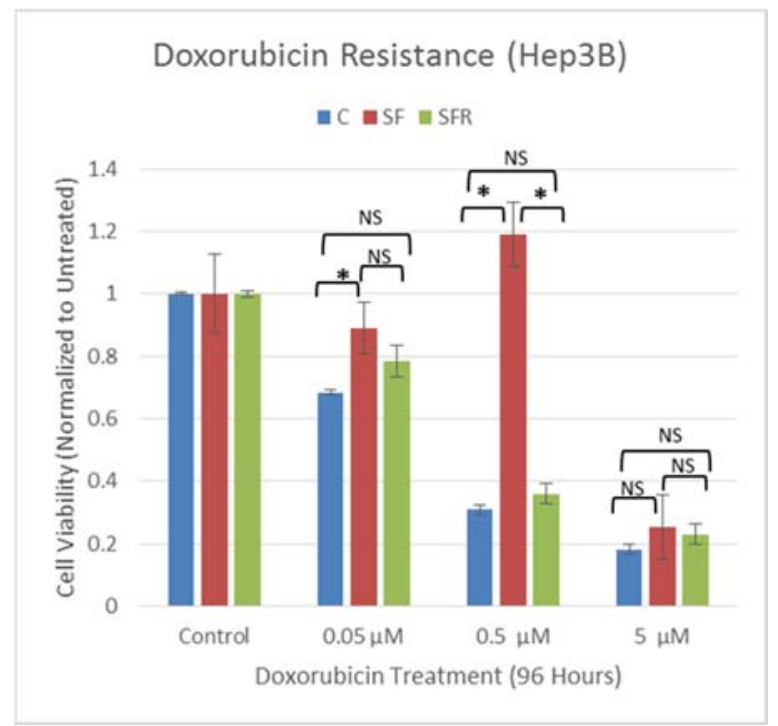

Figure 6. Human HepG2 and Hep3B Spheroids Showed Doxorubicin Resistance Property, Supporting Findings in Mouse Hepa1-6 Cells. HepG2 or Hep3B cells were seeded in 96 well plate in triplicates at 3000 cells/well and studied for their chemotherapy resistance properties by MTT assay. Value 1 on y-axis represents $100 \%$ cell viability. (A) Doxorubicin resistance in HepG2 cells. (B) Doxorubicin resistance in Hep3B cells. For both human cell lines, HepG2 and Hep3B, spheroids showed higher resistance to Doxorubicin compared to corresponding controls. Values have shown in "Mean \pm S.D", ${ }^{*}(p<0.05), \mathbf{N S}=$ No significance $(p>0.05) . \mathbf{C}=$ Control group, $\mathbf{S F}=$ Serum-free group, SFR= Reserum group. 


\section{Enriched HCC Spheroids Showed Higher Expressions of Cancer Stem Cells}

\section{(CSCs) Surface Markers and Functional Markers:}

Surface and functional markers are currently the best available tools to define the origin and lineage of cells in animal tissues, and therefore, these tools are extensively employed to characterize CSCs in solid malignancies including HCC $[11,31,52]$. Most extensively characterized and reported surface markers for HCC CSCs are EpCAM, CD90, CD44, AFP, OV6, and CD133 [27, 31, 53]. It is noteworthy that EpCAM+ and CD90+ cells are physiologically different in terms of their tumorigenic potential and differentiation stage [34], and so is true for other markers. Because of a high degree of heterogeneity, no single maker could confidently and exclusively define HCC CSCs. Extensive research is being done globally in this pursuit.

In order to confirm CSC-like properties in HCC spheroids, we selected extensively reported and studied surface markers i.e. EpCAM, CD90, CD44, and CD133, and tested HCC spheroids for their expression by flow-cytometry and ICC. Our findings suggest that HCC spheroids showed up-regulation in EpCAM levels compared to control, and EpCAM+ cells are enriched in spheroid culture (Figure-7.A). We confirmed our findings with ICC using anti-EpCAM antibodies (Figure-7.B). We have also confirmed up-regulation of CD90, CD44, and CD133 in spheroid culture with enrichment of CD90+, CD44+, CD90+/CD44+, and CD133+ cells (Figure-8). Each of this subpopulations bears different physiological properties and differentiation states e.g. CD44+/CD90+ cells were suggested as more tumorigenic and less differentiated compared to 
CD44+/CD90- or CD44-/CD90+ cells alone [31]. Our findings confirmed that in vitro Hepa1-6 spheroids can enrich all important CSC subpopulations reported so far.

As it is defined by its asymmetric cell division property and hierarchical importance, the CSC theory is a functional concept. Two extensively reported functional markers to define CSCs, ALDH activity and Hoechst 33342 efflux assays $[28,54]$, were also tested in Hepa1-6 CSC spheroids. Hepa1-6 spheroids showed $1.3 \%$ increase in ALDH+ cells (Figure-9.A). Also spheroid cells have showed property of dye exclusion (Figue-9.B), which was confirmed by Western Blot analysis of $A B C G 2$, multi-drug resistant transporter responsible for dye exclusion (Figure-9.C). Dye efflux depends on expression and activity of ABCG2, and clinically correlates with drug resistance including doxorubicin [28]. 


\section{$\underline{A}$}

Control

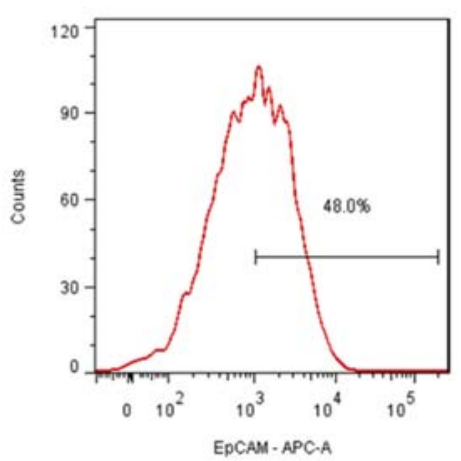

Serum Free (CSCs)

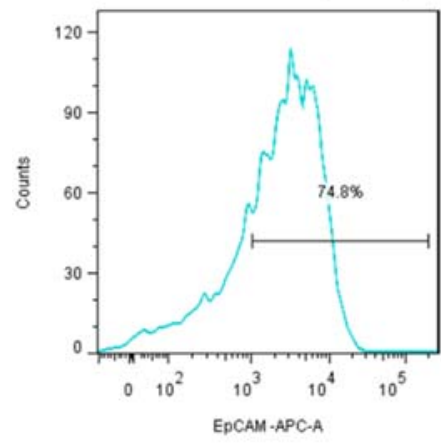

Overlay

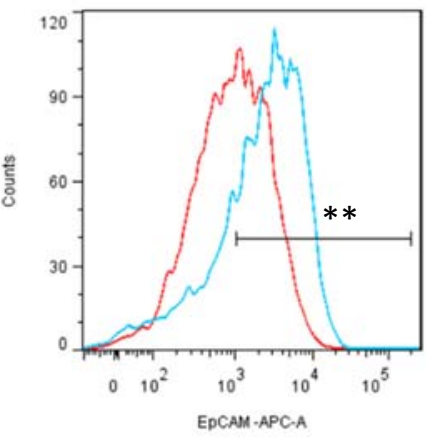

$\underline{B}$

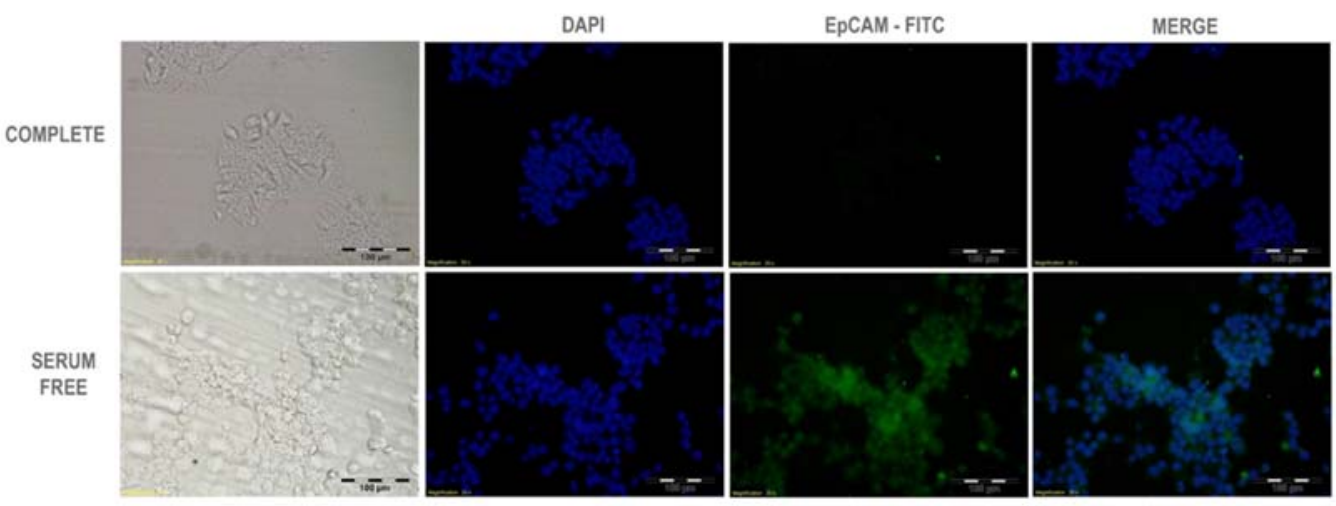

Figure 7. Hepa1-6 Spheroids Showed Increased EpCAM Expression. Hepa1-6 cells were grown in serum-free media (spheroids) or control media for 7 days. After 7 day treatment, cells were harvested and analyzed for EpCAM expression. (A) EpCAM expression analysis by flow-cytometry using APC conjugated Anti-EpCAM antibodies, ** $(p<0.005), n=4$ independent experiments, (B) EpCAM expression analysis by ICC using FITC conjugated Anti-EpCAM antibodies. 7 Day SF treatment. Cells were fixed, stained and analyzed by fluorescence microscopy at 20x magnification $(B a r=100 \mu \mathrm{m})$. DAPI stains nuclei. 

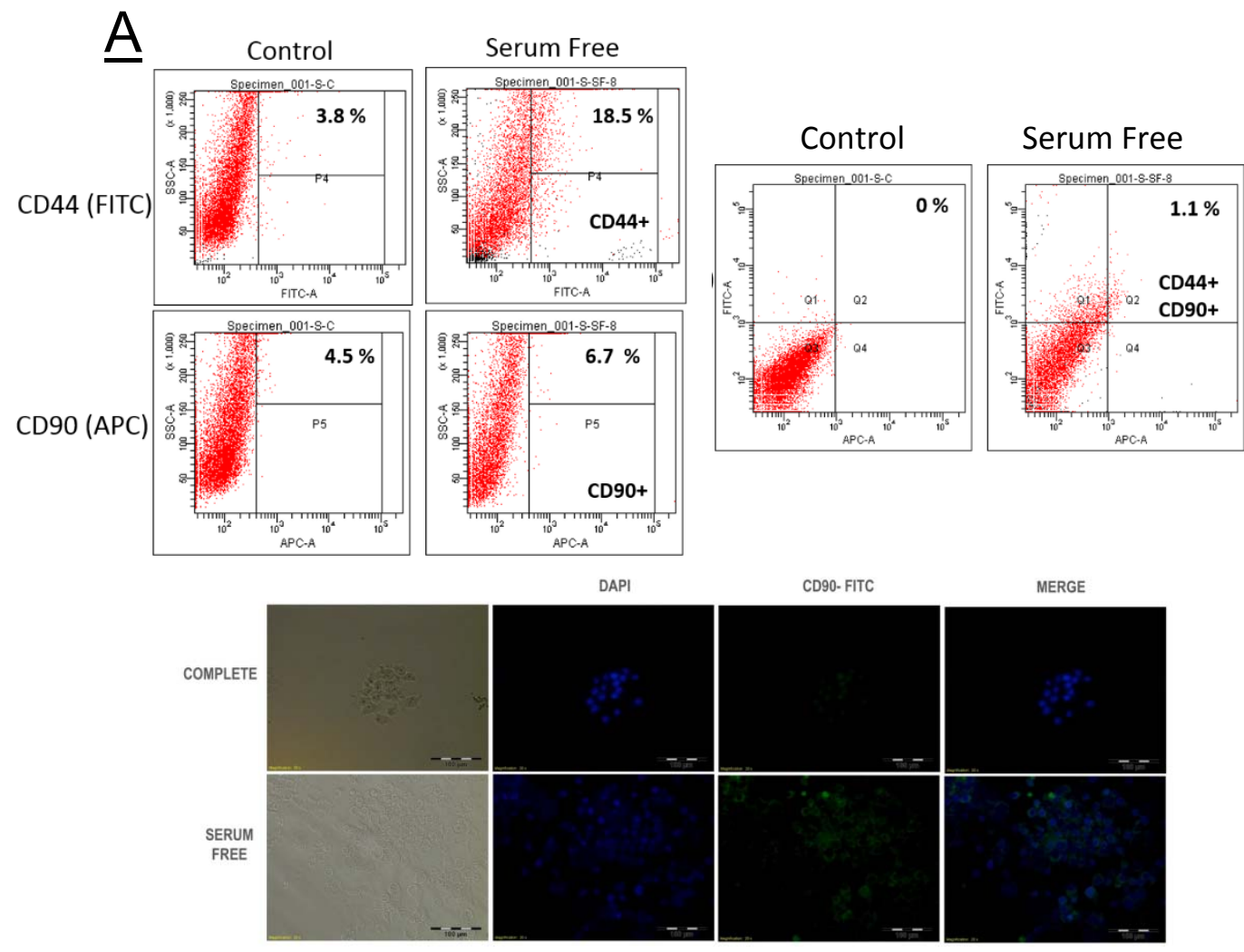

$\underline{B}$

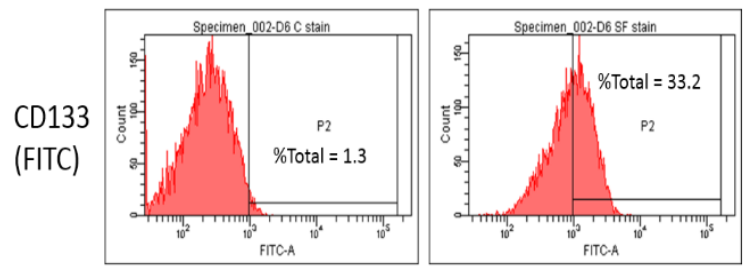

DAP

CD133 - FITC

MERGE

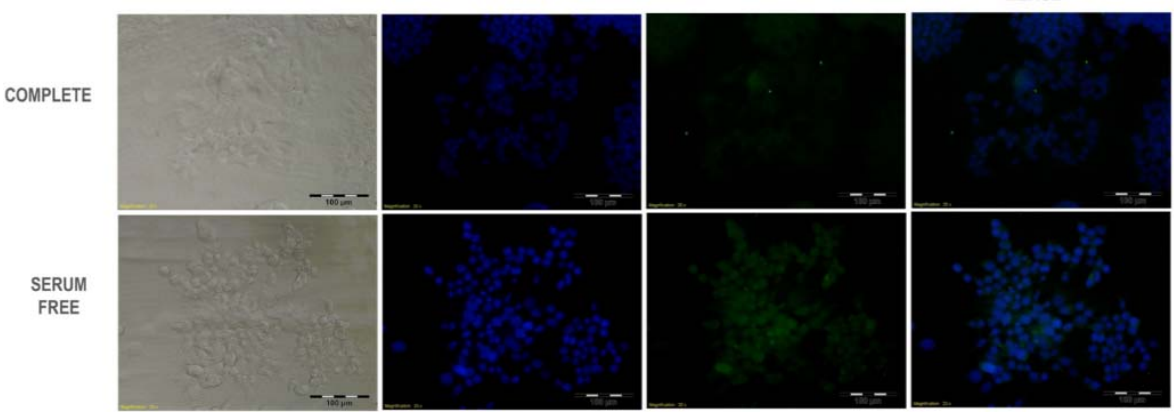

Figure 8. Hepa1-6 Spheroids also Showed Increased CD44, CD90 and CD133

Expression, Well Reported CSC Surface Markers. Hepa1-6 cells were grown in serum-free media (spheroids) or control media for 7 days. After 7 day treatment, cells were harvested and analyzed for corresponding markers. (A) CD44 and CD90 expression analysis by flow-cytometry, and CD90 analysis by ICC. (B) CD133 expression analysis by flow-cytometry and ICC. Cells were fixed, stained and analyzed by fluorescence microscopy at 20x magnification $(B a r=100 \mu \mathrm{m})$. DAPI stains nucleus. 


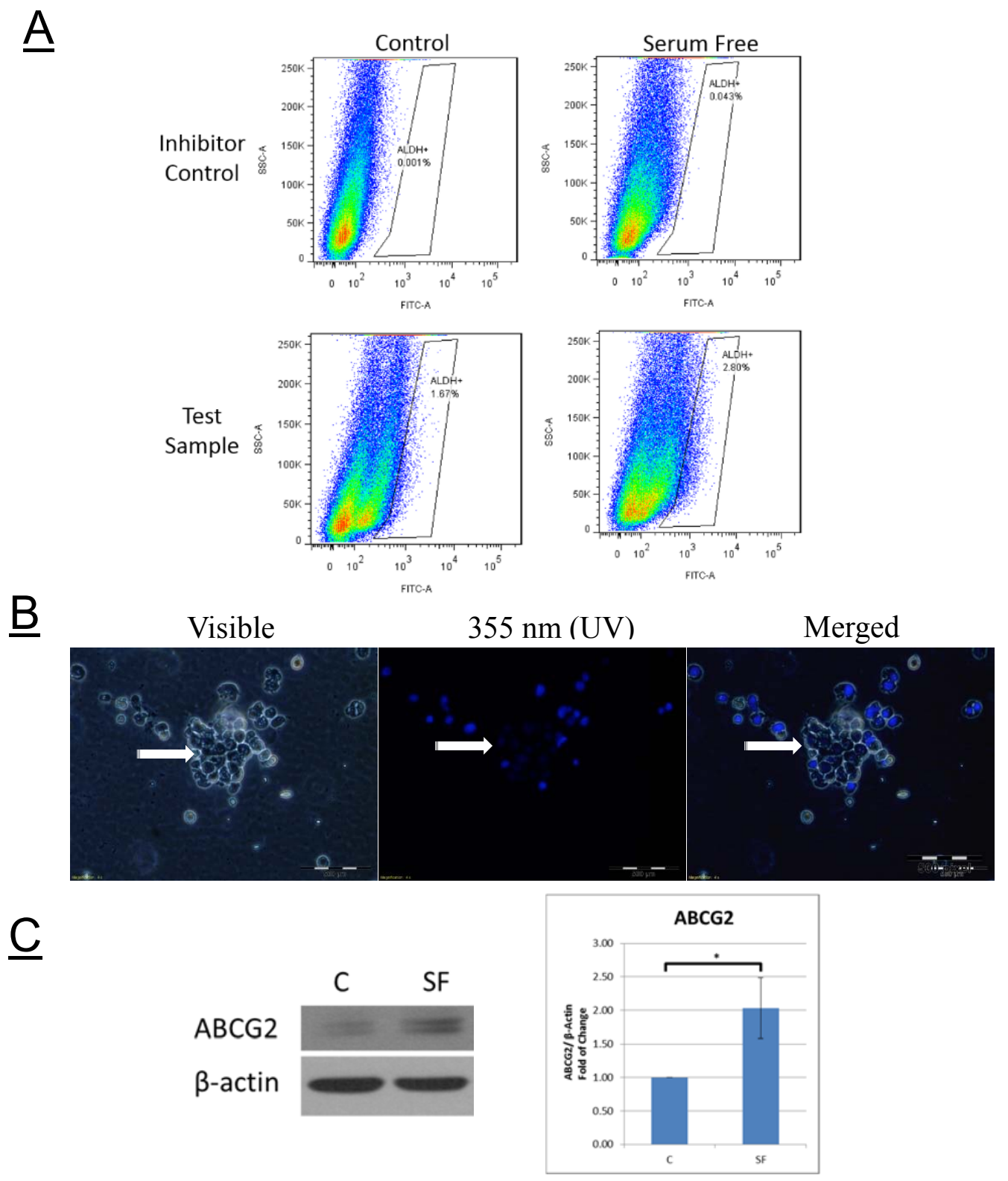

Figure 9. Hepa1-6 Spheroids Showed Increased CSC Functional Markers. Hepa1-6 cells were grown in serum-free media (spheroids) or control media for 7 days. After 7 day treatment, cells were harvested and analyzed. (A) Aldefluore assay showing higher ALDH enzyme activity in CSC spheroids compared to control. (B) Hoechst 33342 efflux assay - ICC representative images of spheroids showing dye efflux, contributed by ABCG2 activity. Stem-like cells with high ABCG2 activity show less staining compared to normal cells (low ABCG2 activity). ICC at 10x magnification (Bar $=200 \mu \mathrm{m}$ ). Hoechst 33342 stains nuclei. (C) Representative Western Blot and densitometry analysis of $A B C G 2$ expression. Increased $A B C G 2$ expression in spheroids compared to control. * $(p \leq 0.05), n=3$ independent experiments. $\mathbf{C}=$ Control; $\mathbf{S F}=$ Serum-free. 


\section{Up-Regulation of $\beta$-catenin in HCC CSC Spheroids:}

Many signaling pathways are implicated and studied in CSCs [55]. Wnt/ $\beta-$ catenin pathway is the cardinal pathway in normal stem cell maintenance and highly implicated in HCC and CSCs $[42,56]$.

Enriched Hepa1-6 CSCs showed increased $\beta$-catenin protein levels both in the cytoplasm $(1.53 \pm 0.21$ fold, $P<0.05)$ as well as in nucleus $(1.54 \pm 0.15$ fold, $p<0.001)$ compared to control cells (Figure-10). We have also tested $\beta$ catenin levels in HepG2 cells and found it to be consistent with our findings in Hepa1-6 cells (data not shown, downstream target studies were not completed in HepG2 cells when this thesis was being written).

To further confirm functional consequences of higher $\beta$-catenin levels in Hepa1-6 CSC spheroids, $\beta$-catenin downstream targets (C-MYC, Cyclin-D1, LEF1) were analyzed by Western Blot analysis. All three downstream targets we tested were proportionately increased with increased $\beta$-catenin levels (Figure11), suggesting that higher $\beta$-catenin levels in CSC spheroids have functional consequences. More importantly, C-MYC and Cyclin-D1 are highly implicated in carcinogenesis [12].

To further investigate the increase in $\beta$-catenin levels, we tested GSK-3 $\beta$ phosphorylation status. Active GSK-3ß (no Ser9 phophorylation) directs cytoplasmic $\beta$-catenin to ubiquitin mediated proteaosomal degradation by phophorylating $\beta$-catenin at S33/S37/T41 positions. However, when GSK-3 $\beta$ itself is phosphorylated at Ser9 position, it loses its substrate specificity for $\beta$ - 
catenin and cytoplasmic $\beta$-catenin gets stabilized, translocates to the nucleus and regulates transcription at the gene level. Hepa1-6 CSC spheroids showed increase in inactive GSK-3 $\beta$ levels (phosphorylated at Ser9) compared to control cells (Figure-12). This finding suggests that GSK-3 $\beta$ activity at least partially contributed to increased $\beta$-catenin levels in Hepa1-6 spheroids and needs to be investigated further. 
A

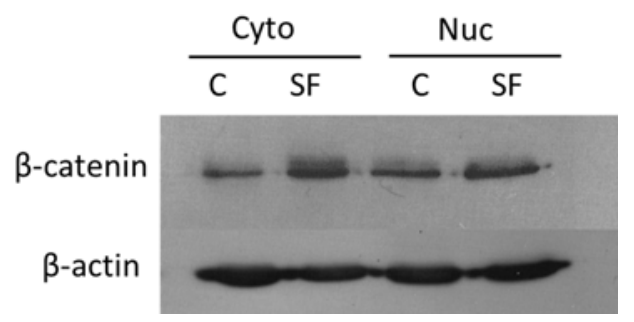

B

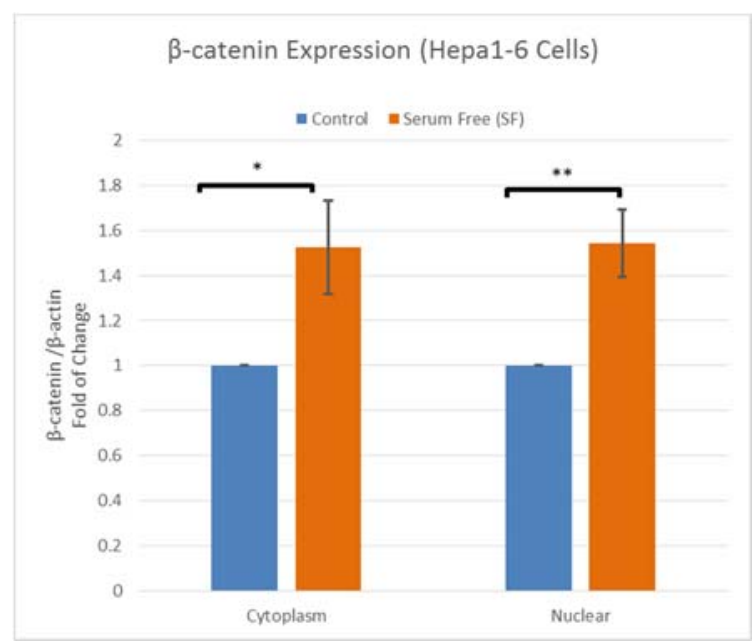

Figure 10. Hepa1-6 Spheroids Showed Increased $\beta$-catenin Levels. Hepa1-6 cells were grown for 7 days in serum-free media (SF) or complete media (control). Cells were harvested after 7 day treatment, and cytoplasmic and nuclear proteins were extracted. (A) Representative Western Blot. (B) Densitometry image analysis. ${ }^{*}(p \leq 0.05),{ }^{* *}(p \leq 0.005)$, $\mathrm{n}=3$ independent experiments. $\beta$-actin used as loading control. Cyto $=$ Cytoplasm; $\mathbf{N u c}=$ Nuclear; $\mathbf{C}=$ Control; $\mathbf{S F}=$ Serum-free. 
$\underline{A}$

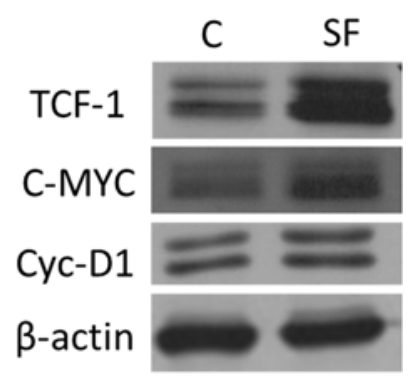

$\underline{B}$

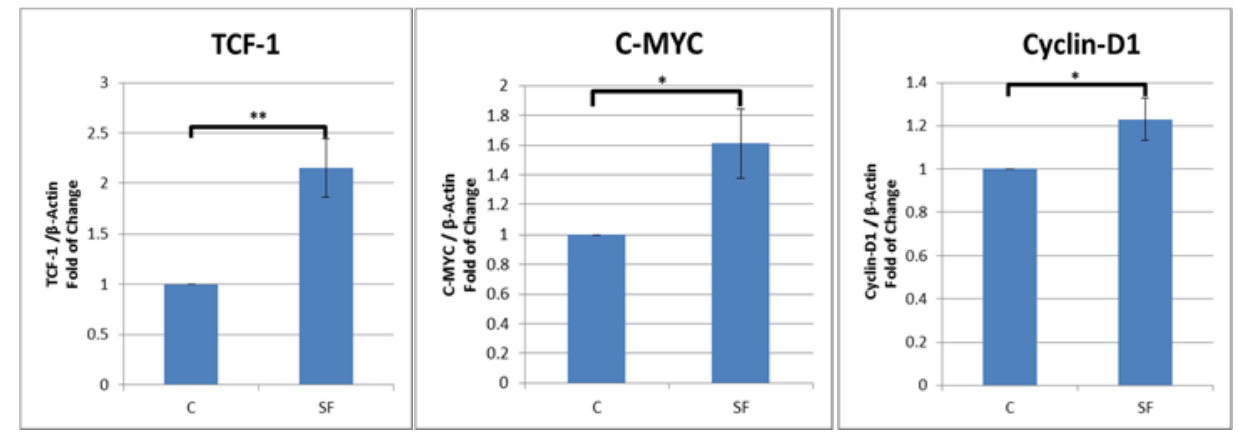

Figure 11. Hepa1-6 Spheroids Showed Increased Expression of $\beta$-catenin

Downstream Targets. Hepa1-6 cells were grown for 7 days in serum-free media (SF) or complete media (control). Cells were harvested after 7 day treatment, and total proteins were extracted using SDS buffer. All three $\beta$-catenin downstream targets i.e. TCF-1, CMYC, and Cyclin-D1, were found to be increased in CSC spheroids compared to control. (A) Representative Western Blot, (B) Densitometry image analysis. $\beta$-actin used as loading control. * $(p \leq 0.05),{ }^{* *}(p \leq 0.005), n=3$ independent experiments. $\mathbf{C}=$ Control; SF $=$ Serum-free. 
$\underline{A}$

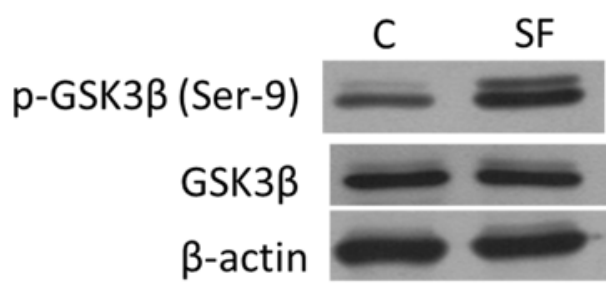

$\underline{B}$
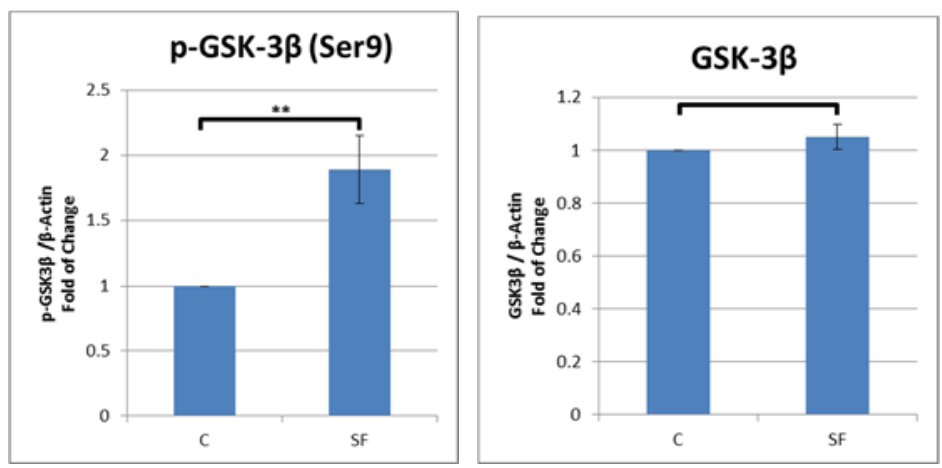

Figure 12. Higher $\beta$-catenin Levels in Hepa1-6 Spheroids May Be Contributed Via GSK-3 $\beta$ Activity. Hepa1-6 cells were grown for 7 days in serum-free media (SF) or complete media (control). Cells were harvested after 7 day treatment, and total proteins were extracted using SDS buffer. No change was observed in total GSK-3 $\beta$ levels, but phosphorylated GSK-3 $\beta$ (Ser9) levels were increased in CSC spheroids compared to control. (A) Representative Western Blot, (B) Densitometry image analysis. ${ }^{* *}(p \leq 0.005)$, $\mathrm{n}=3$ independent experiments. $\beta$-actin used as loading control. $\mathbf{C}=$ Control; $\mathbf{S F}=$ Serum-free. 


\section{HCC CSC Spheroids Possess Higher Tumorigenic Capability in vivo:}

CSCs have been suggested to possess increased tumorigenic properties in vivo. To test tumorigenic potential of Hepa1-6 spheroids, we used an orthotopic C57LJ mouse model. We injected seven days cultured 1X107 Hepa1-6 spheroids and non-spheroid control cells into livers of 8 week old immunocompetent C57LJ mice ( $\mathrm{n}=3$ mice in each group) and monitored for two weeks. Mice injected with Hepa1-6 spheroids developed more aggressive tumors with overall higher tumor volume $\left(5800 \mathrm{~mm}^{3}\right)$ compared to mice injected with non-spheroid cells $\left(1900 \mathrm{~mm}^{3}\right)$ (Figure-13.A). Aggressive nature of CSC tumors was also witnessed at multiple sites within the liver compared to control, suggesting that CSC spheroids possess increased tumor initiation capabilities (Figure-13.A). Increased liver weight was observed in spheroid group $(3.9 \pm 1.6)$ compared to control group $(1.7 \pm 0.43)$, which is likely due to aggressive growth and higher tumor mass in spheroids injected group. This justifies the increased overall body weight by about $2.3 \mathrm{gms}$ in spheroids group compared to control. We were unable to perform statistical tests for significance because one Hepa1-6 spheroids injected mouse died within 2 weeks of injection due to extremely aggressive tumor growth.

We also studied Hep3B spheroids in orthotopic BALB/C nude mouse model. Hep3B spheroids also supported our findings in Hepa1-6 and showed aggressive tumor growths in the spheroid group compared to non-spheroid group (Figure-13.B). EpCAM is extensively reported CSC marker in HCC, and also found to be higher in our Hepa1-6 spheroids. We studied EpCAM expression by 
Western Blot in Hep3B xenograft tissues, and found EpCAM up-regulation in the spheroid group compared to the non-spheroid group (Figure-13.C). 
$\underline{A}$

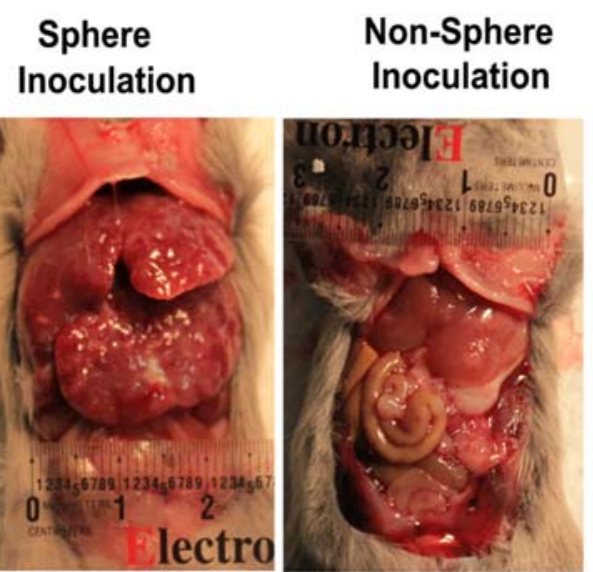

$\underline{B}$

$\begin{array}{cc}\text { Sphere } & \text { Non-Sphere } \\ \text { Inoculation } & \text { Inoculation }\end{array}$
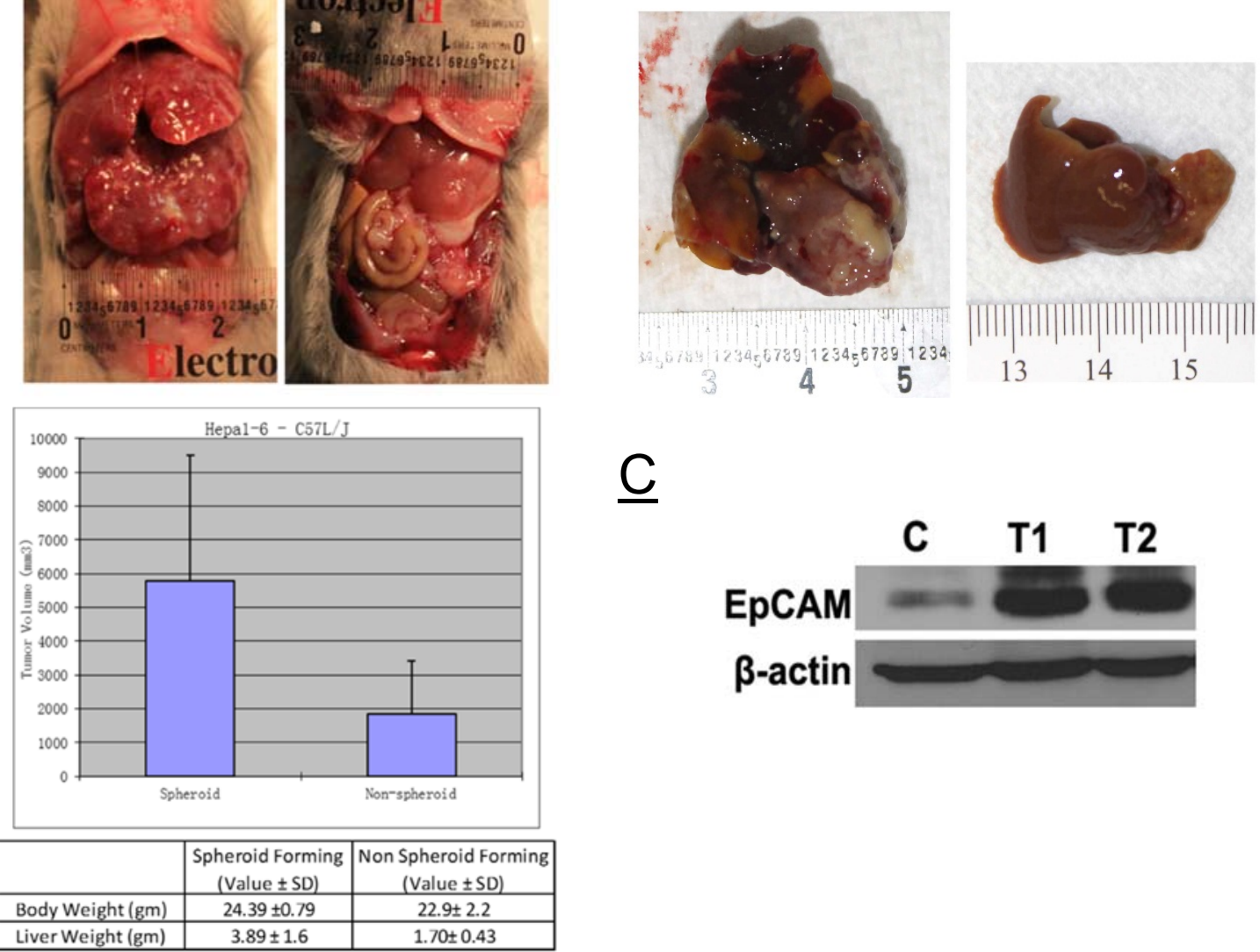

$\underline{\mathrm{C}}$

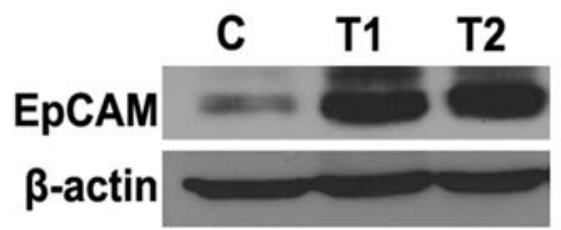

Figure 13. CSC Spheroids Possessed Higher Tumorigenic Capability. Tumors in spheroid group animals were more aggressive and proliferative compared to control. (A) Upper-Orthotopic C57LJ mice with $1 \times 10^{7}$ CSC spheroids or control Hepa1-6 cells injected into liver of each animal ( $n=3$ animals in each group). Lower- quantified tumor volumes. (B) Orthotopic BALB/C nude mice with $1 \times 10^{7} \mathrm{CSC}$ spheroids or control Hep3B cells injected into liver of each animal ( $n=3$ in each group). Tumor tissues of BALB/C xenograft were further studied for EpCAM expression. (C) Western Blot analysis of two Hep3B spheroid tumors and control tumor. EpCAM expression levels were found to be higher in the Hep3B spheroid group. C: Control group; T1 \& T2: Hep3B spheroid tumors. 


\section{Analysis of Human Specimens Found Significant Higher EpCAM Expressions in HCC Tissues:}

Total protein was extracted from 8 pairs of malignant tissues and adjacent benign tissues. Western Blot analysis was performed to analyze the EpCAM and $\beta$-catenin expression in these tissues (Figure-14.A \& B). Results showed that, in 4 paired tissues, EpCAM expression was higher in malignant tissue compared to the benign adjacent tissue (samples 1, 2, 5, and 6). In 3 paired tissues, EpCAM expression was only slightly increased in malignant tissue compared to the benign adjacent tissue (samples 3,4 , and 8 ). However, in one pair (sample 7), EpCAM expression remained unchanged. $\beta$-catenin expression levels were found to be high in 5 paired samples (samples 1, 2, 4, 5, and 6). However, in pair 3 , pair 7 and pair $8, \beta$-catenin expression levels were found to be lower in malignant tissue compared to benign adjacent tissue.

We have also examined 24 pairs of HCC tissues and adjacent benign control by IHC (Figure-14.C). Our data showed significant increase in EpCAM expression in specimens with HCC $(483.75 \pm 119.92$, $p<0.0001)$ when compared with the normal liver tissue within the resected specimens $(38.44 \pm 7.31)$. 

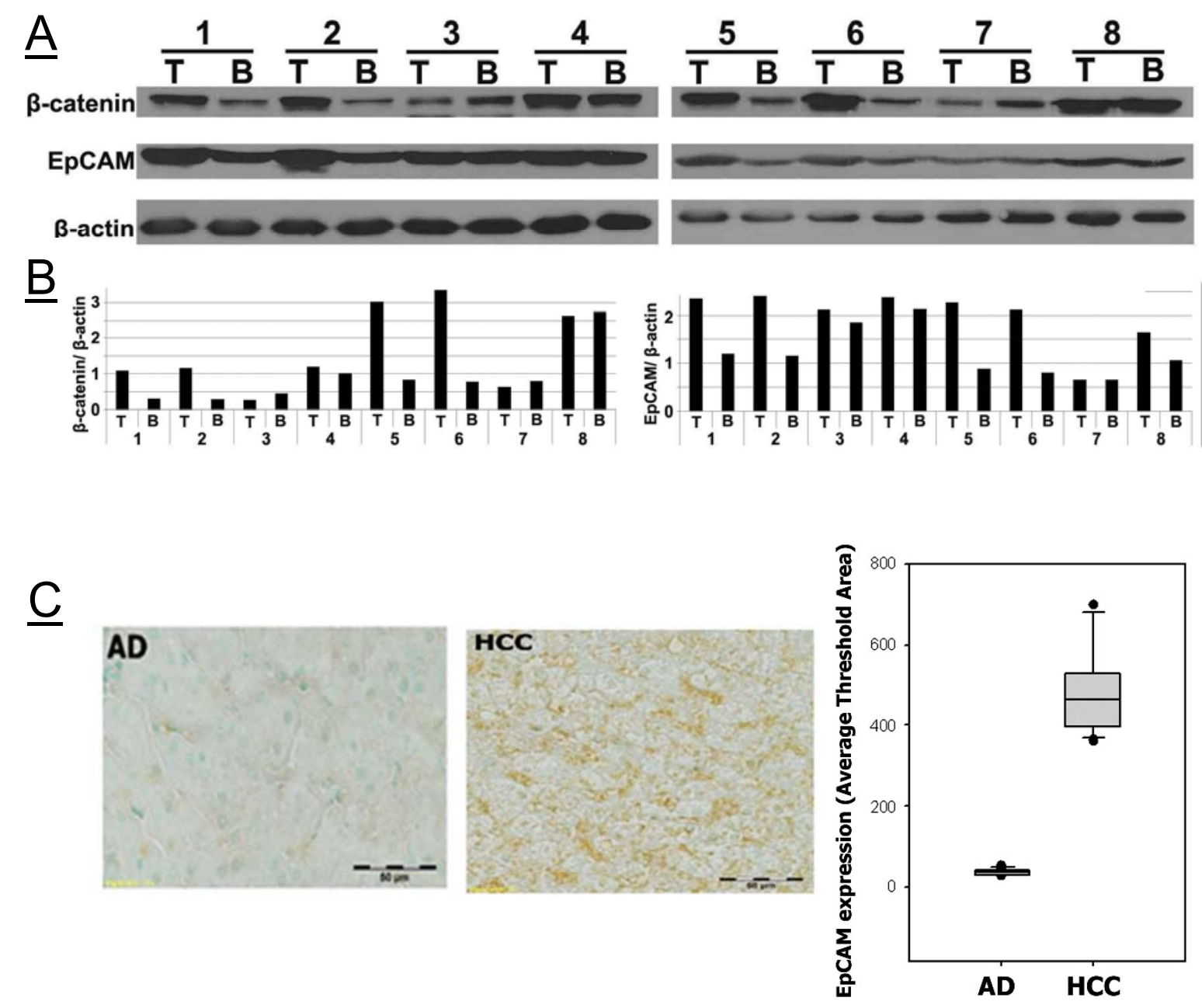

Figure 14. Analysis of Human Specimens. Total proteins were extracted from 8 pairs of human HCC specimens (tumor tissue and adjacent benign tissue) and analyzed SDSPAGE followed by Western Blot for EpCAM and $\beta$-catenin expression. (A) Western blot; (B) densitometry image analysis of EpCAM (left) and $\beta$-catenin (right) expression in malignant tumor tissue and adjacent benign tissue $(n=8)$. T: tumor tissue; $B$ : benign adjacent tissue. Total 24 pairs of HCC specimens were analyzed by IHC staining. (C) Left: Representative images of IHC EpCAM staining of human tissue specimens. Right: Quantified EpCAM expression ( $n=24$, paired benign $A D$ and HCC specimens). 40X magnification $(B a r=50 \mu \mathrm{m})$ AD: adjacent normal liver; HCC: hepatocellular carcinoma. 


\section{CHAPTER IV}

\section{DISCUSSION}

Recent studies have shown that many epithelial cancers including hepatocellular carcinoma ( $\mathrm{HCC}$ ) arise from small subpopulation of cells called cancer stem cells (CSCs) $[10,11,57]$. According to CSC theory, tumors are hierarchically organized with heterogeneous populations of cells where a few subpopulations called CSCs are poorly differentiated and functionally acquire the apex position in the hierarchy of differentiation [13]. These poorly differentiated CSCs are believed to be responsible for tumor growth and maintenance of tumor mass during carcinogenesis. CSCs acquire this apex role by acquiring selfrenewal capability, where asymmetric divisions maintain CSC populations as well as contribute to tumor mass by differentiation [58]. Poorly differentiated CSCs also possess spheroid formation capabilities under serum-free conditions where most differentiated cells cannot survive. CSCs also possess chemoresistance property that results in up-regulation of drug resistant transporters [57, 59]. Much of the advanced knowledge on CSCs comes from the studies that have used FACS technology to isolate and enrich CSCs from primary HCC tumors, and then test their propagation in nude mice $[18,19,34,60]$. This approach, although 
proven the most valuable, is cumbersome, time-consuming, expensive, and do not readily enable either characterization of CSCs or their functional properties. Tumor heterogeneity in primary $\mathrm{HCC}$ and variation in $\mathrm{HCC}$ patients are key reasons for these limitations. In most laboratory conditions, primary tumor cells obtained from patient's HCC tissue, lose their original phenotype during first few passages in culture. In contrast, cell lines derived from hepatoma normally have homogeneous cells and lack heterogeneity observed in clinical tumors. Despite these limitations, cell lines can provide valuable tools to study drug development, characterization, and to investigate biochemical mechanisms.

Serum-free conditions enriched in growth factors allow cells to grow in an anchorage-independent manner, and is a well-documented standard method for maintaining undifferentiated cells [46, 61-63]. Spheroids formed in serum-free culture have been suggested to mimic not only phenotype but also genotype of the primary tumor than cells in normal culture media [48]. One study disagreed with this notion and showed that not all cell lines can enrich CSC-like cells in spheroid culture, and each cancer cell line should be evaluated subjectively [64]. On the other hand, more and more groups are now testing their hypothesis in spheroid culture. A recent study reported that simply generating multicellular spheres followed by reversal to adherent cell line can significantly change phenotype and can be used as in vitro metastatic model [61]. Altogether, spheroid cultures provide a balanced approach to enrich and study CSC-like cells present in primary tumors with added advantage of reproducibility and validity of findings. 
In the present study, we successfully identified HCC cells with CSC-like properties (derived from hepatoma cell lines) using serum-free culture system. Enriched spheroid cells showed self-renewal capability, and serially passed for more than 10 generations in serum-free culture. HCC CSC spheroids showed resistance to chemotherapeutic drug Doxorubicin, with concomitant up-regulation of ABCG2 expression - a multi-drug resistant transporter responsible for efflux of drug from the cell [28]. We also studied putative HCC CSC markers by flowcytometry and ICC. Our findings suggest that $\mathrm{EpCAM}^{+}, \mathrm{CD}^{+} 0^{+}, \mathrm{CD}_{4} 4^{+}$, and CD $133^{+}$CSC subpopulations were successfully enriched in spheroids compared to control group. We also studied reported functional markers (ALDH activity and Hoechst 33342 efflux) and confirmed functionally active CSC-like cells in spheroids. For final benchmark confirmation, we injected equal numbers of spheroids and control cells into established orthotopic mouse models (C57L/J for Hepa1-6, and BALB/C for Hep3B) and showed that enriched CSC spheroids possess high tumorigenic property contributing to aggressive tumor growth in vivo compared to control cells.

We have analyzed 24 pairs of human HCC specimens and confirmed significant up-regulation of EpCAM in HCC tissues compared to adjacent benign liver tissues. EpCAM is an extensively studied CSC marker in HCC, and EpCAM+ cells showed higher tumorigenicity and chemoresistance [18]. Yamashita et al. studied and suggested a novel HCC classification with prognostic implications based on EpCAM+/AFP+ cells in HCC where higher numbers of EpCAM+ HCC cells correlated with worse clinical prognosis [33]. A 
study by Terris et al. suggested EpCAM as a potential Wnt/ $\beta$-catenin signaling target [32]. Our studies in human specimens in 8 pairs of HCC and adjacent benign tissues showed concomitant increase and decrease in EpCAM and $\beta-$ catenin levels. Also, 5 out of 8 pairs showed increased expression in both EpCAM and $\beta$-catenin.

Accumulated evidence have been established that $\mathrm{Wnt} / \beta$-catenin pathway plays a vital role in not only normal stem-cell biology but also in HCC carcinogenesis. We found increased levels of $\beta$-catenin in HCC spheroids, both in the cytoplasm and the nuclei than in control cells. Also, $\beta$-catenin downstream gene targets (C-MYC, Cyclin-D1, LEF1) were also upregulated, further supporting functional consequences of higher $\beta$-catenin levels in CSC spheroids. Finally, we also found changes in GSK-3ß phosphorylation status where HCC CSC spheroids have higher levels of S9-phospho-GSK-3 $\beta$ compared to control. This could be a possible mechanism for higher $\beta$-catenin levels and its downstream effect in HCC spheroids need to be investigated further.

Chemotherapy plays a significant role in decreasing mortality and improving the survival in HCC patients. However, chemoresistance whether acquired or inherent, greatly affects disease free survival and early HCC recurrence in patients. Mechanisms involved in anticancer chemotherapy are multifaceted and largely undefined in HCC. Since chemotherapy resistance is an important property of CSCs, characterizing CSCs and establishing an in vitro tool to study chemotherapy resistance is of great value in translational research. In our present study, enriched HCC spheroids showed phenotypic diversity and 
significant doxorubicin resistance in all three hepatoma cell lines (Hepa1-6, HepG2, and Hep3B). Also we demonstrated higher ABCG2 expressions in CSC spheroids compared to control. Recently, two drug resistance studies in breast cancer have identified functional role of $\beta$-catenin/ABCG2 signaling $[39,40]$. Study by Chua et al. suggested ABCG2 as transcriptional target of $\mathrm{Wnt} / \beta$-catenin signaling [45]. All these studies together with our results strongly suggested Wnt/ $\beta$-catenin signaling pathway is implicated in $\mathrm{HCC}$ chemoresistance via $\mathrm{HCC}$ CSCs.

\section{Summary and Future Directions:}

Our work has successfully identified CSC-like properties in HCC spheroids. These CSC spheroids showed resistance to Doxorubicin, first line drug to treat $\mathrm{HCC}$ in clinics. 24 pairs of human specimens we analyzed have shown increased expression of EpCAM, well established HCC CSC marker. Expression of EpCAM and ABCG2, multi-drug resistant transporter, have been implicated in HCC patients and suggested to be under the regulation of $\mathrm{Wnt} / \beta$ catenin signaling. However, exact mechanisms are not clear at this point in time. We believe that the chemotherapy resistant properties of HCC tumors could be contributed by Wnt/ $\beta$-catenin signaling mediated CSC activation. For future work, we will study the role of Wnt/B-catenin signaling in activation/origin of CSCs in HCC and findings will be used to establish clinical correlation(s) in HCC patients. Expected clinical correlation(s) with HCC prognosis and chemotherapy resistance could help in determining treatment modalities during primary tumor treatment and improve disease free survival in HCC patients. 


\section{REFERENCES}

1. U.S. Cancer Statistics Working Group, United States Cancer Statistics: 19992010 Incidence and Mortality Web-based Report, in www.cdc.gov/uscs. 2013.

2. El-Serag, H.B., Hepatocellular Carcinoma. New England Journal of Medicine, 2011. 365(12): p. 1118-1127.

3. Regimbeau, J.M., et al., Obesity and diabetes as a risk factor for hepatocellular carcinoma. Liver Transpl, 2004. 10(2 Suppl 1): p. S69-73.

4. Dyson, J., et al., Hepatocellular cancer: the impact of obesity, type 2 diabetes and a multidisciplinary team. J Hepatol, 2014. 60(1): p. 110-7.

5. Ligibel, J.A., et al., American Society of Clinical Oncology position statement on obesity and cancer. J Clin Oncol, 2014. 32(31): p. 3568-74.

6. El-Serag, H.B. and K.L. Rudolph, Hepatocellular carcinoma: epidemiology and molecular carcinogenesis. Gastroenterology, 2007. 132(7): p. 2557-76.

7. Fattovich, G., et al., Hepatocellular carcinoma in cirrhosis: incidence and risk factors. Gastroenterology, 2004. 127(5 Suppl 1): p. S35-50.

8. Forner, A., et al., Current strategy for staging and treatment: the BCLC update and future prospects. Semin Liver Dis, 2010. 30(1): p. 61-74.

9. Tong, C.M., S. Ma, and X.Y. Guan, Biology of hepatic cancer stem cells. J Gastroenterol Hepatol, 2011. 26(8): p. 1229-37.

10. Lobo, N.A., et al., The biology of cancer stem cells. Annu Rev Cell Dev Biol, 2007. 23: p. 675-99. 
11. Magee, J.A., E. Piskounova, and S.J. Morrison, Cancer stem cells: impact, heterogeneity, and uncertainty. Cancer Cell, 2012. 21(3): p. 283-96.

12. Hanahan, D. and Robert A. Weinberg, Hallmarks of Cancer: The Next Generation. Cell, 2011. 144(5): p. 646-674.

13. Dalerba, P., R.W. Cho, and M.F. Clarke, Cancer stem cells: models and concepts. Annu Rev Med, 2007. 58: p. 267-84.

14. Lapidot, T., et al., A cell initiating human acute myeloid leukaemia after transplantation into SCID mice. Nature, 1994. 367(6464): p. 645-8.

15. Al-Hajj, M., et al., Prospective identification of tumorigenic breast cancer cells. Proc Natl Acad Sci U S A, 2003. 100(7): p. 3983-8.

16. Dalerba, P., et al., Phenotypic characterization of human colorectal cancer stem cells. Proc Natl Acad Sci U S A, 2007. 104(24): p. 10158-63.

17. Hermann, P.C., et al., Distinct populations of cancer stem cells determine tumor growth and metastatic activity in human pancreatic cancer. Cell Stem Cell, 2007. 1(3): p. 313-23.

18. Yamashita, T., et al., EpCAM-positive hepatocellular carcinoma cells are tumorinitiating cells with stem/progenitor cell features. Gastroenterology, 2009. 136(3): p. 1012-24.

19. Yang, Z.F., et al., Significance of CD90+ cancer stem cells in human liver cancer. Cancer Cell, 2008. 13(2): p. 153-66.

20. Yang, Z.F., et al., Identification of local and circulating cancer stem cells in human liver cancer. Hepatology, 2008. 47(3): p. 919-28.

21. Barker, N., et al., Identification of stem cells in small intestine and colon by marker gene Lgr5. Nature, 2007. 449(7165): p. 1003-7.

22. Driessens, G., et al., Defining the mode of tumour growth by clonal analysis. Nature, 2012. 488(7412): p. 527-30. 
23. Schepers, A.G., et al., Lineage tracing reveals Lgr5+ stem cell activity in mouse intestinal adenomas. Science, 2012. 337(6095): p. 730-5.

24. Ji, J. and X.W. Wang, Clinical implications of cancer stem cell biology in hepatocellular carcinoma. Semin Oncol, 2012. 39(4): p. 461-72.

25. Yoon, S.K., The biology of cancer stem cells and its clinical implication in hepatocellular carcinoma. Gut Liver, 2012. 6(1): p. 29-40.

26. Ma, S., et al., Identification and characterization of tumorigenic liver cancer stem/progenitor cells. Gastroenterology, 2007. 132(7): p. 2542-56.

27. Chiba, T., et al., Cancer stem cells in hepatocellular carcinoma: Recent progress and perspective. Cancer Lett, 2009. 286(2): p. 145-53.

28. Haraguchi, N., et al., Characterization of a side population of cancer cells from human gastrointestinal system. Stem Cells, 2006. 24(3): p. 506-13.

29. Ma, S., Biology and clinical implications of CD133(+) liver cancer stem cells. Exp Cell Res, 2013. 319(2): p. 126-32.

30. Zhao, X., et al., Integrative genomics identifies YY1AP1 as an oncogenic driver in EpCAM AFP hepatocellular carcinoma. Oncogene, 2015.

31. Liu, L.L., et al., The power and the promise of liver cancer stem cell markers. Stem Cells Dev, 2011. 20(12): p. 2023-30.

32. Terris, B., C. Cavard, and C. Perret, EpCAM, a new marker for cancer stem cells in hepatocellular carcinoma. J Hepatol, 2010. 52(2): p. 280-1.

33. Yamashita, T., et al., EpCAM and alpha-fetoprotein expression defines novel prognostic subtypes of hepatocellular carcinoma. Cancer Res, 2008. 68(5): p. $1451-61$.

34. Yamashita, T., et al., Discrete nature of EpCAM+ and CD90+ cancer stem cells in human hepatocellular carcinoma. Hepatology, 2013. 57(4): p. 1484-97. 
35. Abdullah, L.N. and E.K. Chow, Mechanisms of chemoresistance in cancer stem cells. Clin Transl Med, 2013. 2(1): p. 3.

36. Yamashita, T. and X.W. Wang, Cancer stem cells in the development of liver cancer. J Clin Invest, 2013. 123(5): p. 1911-8.

37. Di, C. and Y. Zhao, Multiple drug resistance due to resistance to stem cells and stem cell treatment progress in cancer (Review). Experimental and Therapeutic Medicine, 2014.

38. Hashimoto, N., et al., Cancer stem-like sphere cells induced from dedifferentiated hepatocellular carcinoma-derived cell lines possess the resistance to anti-cancer drugs. BMC Cancer, 2014. 14: p. 722.

39. Wang, N., et al., Dietary compound isoliquiritigenin targets GRP78 to chemosensitize breast cancer stem cells via beta-catenin/ABCG2 signaling. Carcinogenesis, 2014. 35(11): p. 2544-54.

40. Wang, Z., et al., Caveolin-1 mediates chemoresistance in breast cancer stem cells via beta-catenin/ABCG2 signaling pathway. Carcinogenesis, 2014. 35(10): p. 2346-56.

41. Warrier, S., et al., Cancer stem-like cells from head and neck cancers are chemosensitized by the Wnt antagonist, sFRP4, by inducing apoptosis, decreasing stemness, drug resistance and epithelial to mesenchymal transition. Cancer Gene Ther, 2014. 21(9): p. 381-8.

42. Nejak-Bowen, K.N. and S.P. Monga, Beta-catenin signaling, liver regeneration and hepatocellular cancer: sorting the good from the bad. Semin Cancer Biol, 2011. 21(1): p. 44-58.

43. Gangavarapu, K.J., et al., Aldehyde dehydrogenase and ATP binding cassette transporter G2 (ABCG2) functional assays isolate different populations of 
prostate stem cells where ABCG2 function selects for cells with increased stem cell activity. Stem Cell Res Ther, 2013. 4(5): p. 132.

44. Takigawa, Y. and A.M. Brown, Wnt signaling in liver cancer. Curr Drug Targets, 2008. 9(11): p. 1013-24.

45. Chau, W.K., et al., c-Kit mediates chemoresistance and tumor-initiating capacity of ovarian cancer cells through activation of Wnt/beta-catenin-ATP-binding cassette G2 signaling. Oncogene, 2013. 32(22): p. 2767-81.

46. Dontu, G., et al., In vitro propagation and transcriptional profiling of human mammary stem/progenitor cells. Genes Dev, 2003. 17(10): p. 1253-70.

47. Ponti, D., et al., Isolation and in vitro propagation of tumorigenic breast cancer cells with stem/progenitor cell properties. Cancer Res, 2005. 65(13): p. 5506-11.

48. Lee, J., et al., Tumor stem cells derived from glioblastomas cultured in bFGF and EGF more closely mirror the phenotype and genotype of primary tumors than do serum-cultured cell lines. Cancer Cell, 2006. 9(5): p. 391-403.

49. Kondo, T., Stem cell-like cancer cells in cancer cell lines. Cancer Biomark, 2007. 3(4-5): p. 245-50.

50. Maric, D., et al., Self-renewing and differentiating properties of cortical neural stem cells are selectively regulated by basic fibroblast growth factor (FGF) signaling via specific FGF receptors. J Neurosci, 2007. 27(8): p. 1836-52.

51. Greene, R.F., et al., Plasma pharmacokinetics of adriamycin and adriamycinol: implications for the design of in vitro experiments and treatment protocols. Cancer Res, 1983. 43(7): p. 3417-21.

52. Oliva, J., et al., The identification of stem cells in human liver diseases and hepatocellular carcinoma. Exp Mol Pathol, 2010. 88(3): p. 331-40.

53. Kamohara, Y., et al., The search for cancer stem cells in hepatocellular carcinoma. Surgery, 2008. 144(2): p. 119-24. 
54. Ma, S., et al., Aldehyde dehydrogenase discriminates the CD133 liver cancer stem cell populations. Mol Cancer Res, 2008. 6(7): p. 1146-53.

55. Pattabiraman, D.R. and R.A. Weinberg, Tackling the cancer stem cells [mdash] what challenges do they pose? Nat Rev Drug Discov, 2014. 13(7): p. 497-512.

56. Mokkapati, S., et al., beta-catenin activation in a novel liver progenitor cell type is sufficient to cause hepatocellular carcinoma and hepatoblastoma. Cancer Res, 2014.

57. Scheel, C. and R.A. Weinberg, Cancer stem cells and epithelial-mesenchymal transition: concepts and molecular links. Semin Cancer Biol, 2012. 22(5-6): p. 396-403.

58. Marjanovic, N.D., R.A. Weinberg, and C.L. Chaffer, Cell plasticity and heterogeneity in cancer. Clin Chem, 2013. 59(1): p. 168-79.

59. Gupta, P.B., et al., Identification of selective inhibitors of cancer stem cells by high-throughput screening. Cell, 2009. 138(4): p. 645-59.

60. Suetsugu, A., et al., Characterization of CD133+ hepatocellular carcinoma cells as cancer stem/progenitor cells. Biochem Biophys Res Commun, 2006. 351(4): p. 820-4.

61. Kunjithapatham, R., et al., Reversal of anchorage-independent multicellular spheroid into a monolayer mimics a metastatic model. Sci Rep, 2014. 4: p. 6816.

62. Chen, Q., et al., Selective proliferation of rat hepatocyte progenitor cells in serum-free culture. Nat Protoc, 2007. 2(5): p. 1197-205.

63. Kanwar, S.S., et al., The Wnt/beta-catenin pathway regulates growth and maintenance of colonospheres. Mol Cancer, 2010. 9: p. 212.

64. Calvet, C.Y., F.M. Andre, and L.M. Mir, The culture of cancer cell lines as tumorspheres does not systematically result in cancer stem cell enrichment. PLoS One, 2014. 9(2): p. e89644. 


\section{CURRICULUM VITAE Harshul Pandit, M.Sc. \\ 779 Theodore Burnett Ct, Apt \# 7 \\ Louisville, Kentucky 40217 \\ Ph: (502) 657-8783 \\ harshul.pandit@louisville.edu}

\section{EDUCATION}

2011-Present Ph.D. in Pharmacology \& Toxicology, University of Louisville, Louisville, KY, USA.

2005-2007 M.Sc. in Biochemistry (thesis), M.S.University of Baroda, Baroda, India.

2004-2005 PG. Diploma in Applied Biochemistry, M.S.University of Baroda, Baroda, India.

2001-2004 B.Sc. in Biotechnology, Sardar Patel University, Vallabh Vidhyanagar, India.

\section{ACADEMIC APPOINTMENTS}

2013-Present Graduate Research Assistant, Division of Surgical Oncology, Department of Surgery, University of Louisville, Louisville, KY.

2012-2012 Graduate Teaching Assistant, Department of Biochemistry, University of Louisville, Louisville, KY.

2010-2011 Instructor (Mathematics), PT Education Center, Bhuj, India.

\section{EMPLOYMENT}

2009-2010 Research Associate E-I, R\&D Division, Protein purification - Down Stream Process Lab, Intas Biopharmaceuticals Ltd, Ahmedabad, India. 2008-2009 Trainee Research Associate E-II, R\&D Division, Protein purification Down Stream Process Lab, Intas Biopharmaceuticals Ltd, Ahmedabad, India. 


\section{OTHER POSITIONS}

2014-2015 Graduate Student Representative (Elected) for School of Medicine Faculty Forum, School of Medicine, University of Louisville, KY.

2013-Present Laboratory procurement, Surgical Oncology Lab, Department of Surgery, Louisville, KY.

2004-2007 Laboratory and Chemical In-charge, Department of Biochemistry, M.S.University of Baroda, Baroda, India.

\section{HONORS AND AWARDS}

2014 Conference Travel Award, HSC Research Office, University of Louisville, Louisville, Louisville, KY.

2014 Conference Travel Award, Graduate Student Council - SIGS, University of Louisville, Louisville, Louisville, KY..

2013 Antibody credits for buying research chemicals and antibodies, Cruz credit program, Santacruz Biotech, TX.

2011-2013 Interdisciplinary Program in Biomedical Sciences (IPIBS) fellowship, University of Louisville, Louisville, KY.

2009 Selected for $35^{\text {th }}$ Mahabaleshwar Seminar at national level, organized by Tata Institute of Fundamental Research (TIFR) Mumbai, India.

2006-2007 Selected for $3^{\text {rd }}$ Bangalore Benny Shilo course in Developmental Biology at International level, organized by Weizmann Institute, Israel \& National Center for Biological Sciences (NCBS), Bangalore, India. Charutar Vidhya Mandal (CVM) award - "Scholar student in the college", N.V.Patel College of Pure and Applied Sciences, Vallabh Vidhyanagar, India.

\section{PUBLICATIONS}

1. Pandit H., Li Y., Agle S., Zhang W., Li X., Cui G., Li S., Li Y., Martin R.. Manganese Superoxide Dismutase (MnSOD) expression is negatively associated with microRNA-301a levels in human Pancreatic Ductal Adenocarcinoma (PDAC). In press.

2. Doughtie A., Li Y., Zhang W., Li X., Pandit H., Li S., Cui G., Martin R.. Upregulation of Fibroblast Growth Factor 19 in Fatty Liver and Hepatocellular Carcinoma. Submitted and in communication. 


\section{ABSTRACTS AND PRESENTATIONS}

\section{$\underline{\text { Research Posters/Abstracts }}$}

1. Li Y., Pandit H., Li X., Li S., Zhang J., Cui G., Martin R., Abolish cancer progenitor cells in a mouse model of diabetes associated hepatocellular carcinoma., AACR Annual Meeting 2015, Philadelphia, PA. Apr-2015.

2. Pandit H., Li Y., Li S., Li X., Zhang W., Martin R.. Identifying Cancer Stem Cell (CSC) like characters in Hepatocellular Carcinoma (HCC) cells and their role in HCC recurrence, Clinical Congress 2014, American College of Surgeons, San Francisco, CA. Oct-2014.

3. Pandit H., Li Y., Li S., Li X., Zhang W., Martin R.. Identifying Cancer Stem Cell (CSC) like characters in Hepatocellular Carcinoma (HCC) cells, and their role in chemotherapy resistance., Research Louisville 2014, Louisville, KY. Aug-2014.

4. Pandit H., Hadpe S., Patel C.. Multivariate Data Analysis (MVDA) of Biopharmaceutical downstream process. Annual conference, Intas Biopharmaceuticals, Ahmedabad, India. Nov - 2010.

5. Hadpe S., Pandit H., Patel C.. Implementation of Quality by Design (QbD) approach in biopharmaceutical operations. Annual conference, Intas Biopharmaceuticals, Ahmedabad, India. Nov -2010.

Oral Presentations - Department Seminar:

1. New insights in miRNA processing - what is happening prior to Drosha and Dicer? Department of Biochemistry \& Molecular Biology, University of Louisville. - Dec 2012.

\section{REFERENCES}

Available upon request. 